\title{
Ambient Complexation Reaction of Zinc Acetate and Ascorbic acid Leads to a New Form of Nanoscale Particles with Emergent Optical Properties
}

Srestha Basu ${ }^{\mathrm{a} \$}$, Archismita Hajra ${ }^{\mathrm{b} \$}$ and Arun Chattopadhyay, ${ }^{\mathrm{a}, \mathrm{b}^{*}}$

\section{${ }^{\$}$ Equal Contribution}

${ }^{a}$ Department of Chemistry, Indian Institute of Technology Guwahati, Guwahati 781039, India

${ }^{\mathrm{b}}$ Centre for Nanotechnology, Indian Institute of Technology Guwahati, Guwahati 781039, India

E-mail: arun@iitg.ac.in 
Abstract: We report the formation of nanoscale particles born out of complexation reaction between zinc acetate and ascorbic acid under ambient conditions and in the aqueous medium. The reaction led to the formation of a molecular complex with formula assigned to be $\mathrm{Zn}_{3}(\mathrm{AA})(\mathrm{OAc})_{2}$ with AA meaning ascorbate, based on mass spectrometry results. Following this, formation of luminescent nanoscale particles - the size of which increased with time was observed. In $24 \mathrm{~h}$ of observations, the sizes increased to about $50 \mathrm{~nm}$ with the presence of different sizes at all times. Transmission electron microscopy results also indicated the formation of polycrystalline nanoparticles in the medium. Further, appearance of a UV absorption peak at $380 \mathrm{~nm}$ and photoluminescence peak at $473 \mathrm{~nm}$ marked the formation of the nanoparticles. The luminescence was also observed to be wavelength tuneable. FTIR and NMR spectroscopic results also supported the formation of a molecular complex with the above formula. The present work highlights the importance of emergent properties of nanoscale molecular materials on the way to crystallization. Also, the present discovery is expected to contribute to the development of safe nanomaterials.

Keywords: ascorbic acid; zinc acetate; complexation reaction; nanoparticles; photoluminescence 


\section{Introduction:}

Progresses in nanoscale science and technology have continuously been supplemented by discoveries of new species with extraordinary properties. ${ }^{1-6}$ Amongst them, colloidal gold (Au) has been known since antiquity; however, its optical properties have been explained based on light scattering about a hundred years back. On the other hand, its dimensiondependent properties at the nanoscale have been realized recently through the syntheses of well - defined structures. ${ }^{7}$ The knowledge has helped reveal the potentials of nanoscale Au particles in fields as diverse as catalysis, ${ }^{8}$ healthcare ${ }^{9,10}$ and optoelectronics. ${ }^{11}$ In that respect, colloidal semiconductor quantum dots (Qdots) and their counterparts fabricated using topdown approaches have generated much excitement in wide range of fields as mentioned above, leading to commercialization of display devices. ${ }^{12,13}$ Additionally, iron oxide nanoparticles are well-known for their superparamagnetism properties at the nanoscale dimensions. ${ }^{14,15}$ Similarly, allotropes of carbon such as $\mathrm{C}_{60},{ }^{16}$ carbon nanotube $^{17}$ and graphene ${ }^{18}$ have received great attention as new materials of choice for their potential applications. The realization of two-dimensional (2D) graphene has helped expand the repertoire in terms of new materials such as silicene, germanene and $2 \mathrm{D} \mathrm{MoS}_{2}{ }^{19,20}$

On the other hand, synthetic chemistry repertoire has been helpful in expanding the reach of the nanoscale materials. For example, perovskite nanostructures, carbon nanodots and nanoscale metal organic and similar frameworks have given rise to a plethora of application potentials especially applicable in the fields of healthcare, energy and the environment. ${ }^{21-23}$ Further DNA-based nanostructures are shown to have important application potentials in healthcare especially targeted delivery and probe. ${ }^{24-26}$ Inorganic nanoparticles are known to typically display dimension dependent physical and chemical properties. Organic nanoparticles such as liposomes, dendrimers, micelles and proteins do not display such properties. ${ }^{27}$ On the other hand, they can be excellent choices for size dependent drug delivery, host for water insoluble drugs and in addition, they can be used as templates for size and shape selected synthesis of inorganic nanoparticles. ${ }^{28-30}$ Notably, the field of molecular nanoparticles has also witnessed extensive growth in the recent past. For instance, crystalline luminescent nanoparticles of organic molecules have been developed following confinement of amorphous nanoparticulate molecules in rigid polymer matrix and subsequential treatment with solvent vapor. The organic molecules were found to exhibit augmented luminescence in 
the nanoparticulate form. Moreover, colloidal nanoscale particles of zwitterionic molecules have been synthesised via reprecipitation method assisted by polyelectrolytes. ${ }^{31,32}$ In addition, molecules exhibiting aggregation induced emission can be tailored to synthesize such nanoscale particles for imaging probe and other optoelectronic applications. ${ }^{33,34}$

The proposition that molecular nanotechnology could revolutionize the bottom-up approaches in the manufacturing of advanced materials and devices needs novel strategies not only in bond making and breaking but also in interactions between chemical bonds that will help design objects at the highest resolution. In this regard, the developments of important structures such as rotaxane and catenane have given rise to the excitement of building machines and their components with the precision at the scale of a molecular bond. ${ }^{35,36}$ However, whether such a principle could lead to viable devices is still an open question, given the complexity of chemical interactions at the molecular level. Thus, the growth of the repertoire of molecules, methods and their assemblies in diverse dimensions ought to continue with the arriving of new methods, molecules and materials. In this regard, development of nanoscale particles based on interactions amongst inorganic complexes could bring new properties, which may be useful in molecular nanotechnology. For examples, assynthesized inorganic metal complexes may interact in a liquid medium and give rise to the formation of nanoscale particles with emergent properties not present in the complexes themselves. This may pave a new way of assemblage based on interacting complexes with each component contributing chemical and physical properties based on the metal center and its oxidation state and the ligand of choice. The emergent property may or may not have the signatures of the participating complexes. However, given the molecular nature of the interactions appropriate choice could be made leading to specific interactions in three dimensions. Such an approach is yet to be reported in the literature.

Herein we report, the unprecedented emergence of photoluminescence of nanoscale assembly of metal complexes when the reaction was carried out in an aqueous medium. Thus chemical reactions - under ambient conditions - involving ascorbic acid and zinc acetate in the aqueous medium led to the formation of $\mathrm{Zn}_{3}(\mathrm{AA})(\mathrm{OAc})_{2}$ complex; $\mathrm{AA}$ is ascorbate. The so-formed complex resulted in the formation of nanoscale particles with time, having strong luminescence in the blue region of wavelengths. The formation of the complex was ascertained by mass spectrometric and NMR spectroscopic analyses. The formation of the nanoscale particles was confirmed by transmission electron microscopy. Such analysis also 
revealed the polycrystalline nature of the particles formed in the dispersion medium. Interestingly, the luminescence was observed to be dependent on excitation wavelength similar to the observations in carbon dots. Time resolved photoluminescence measurements indicated gradual shortening of life time of the excited state thus indicating interactions amongst the complexes leading to the formation of nanoparticles. Further, FTIR analyses indicated possible coordination of hydroxyl groups of ascorbate and acetate with zinc ions, leading to the formation of the complex mentioned above. Also, the role of hydrogen bonding for the association of the $\mathrm{Zn}_{3}(\mathrm{AA})(\mathrm{OAc})_{2}$ moieties, resulting in the formation of nanoparticles, was evident from the FTIR analysis.

\section{Experimental Section:}

2.1. Materials: Zinc acetate dihydrate (Merck), ascorbic acid (Merck), deuterium oxide (Sigma Aldrich), methanol (HPLC grade, Merck) were used as procured without any further purification. Milli-Q water (resistivity $18.2 \mathrm{M} \Omega \mathrm{cm}^{-1}$ at $25^{\circ} \mathrm{C}$ ) was used for all experimental purposes.

\subsection{Instruments:}

Fluorescence emission and excitation spectra of all samples were acquired using HORIBAFluoromax 4 spectrophotometer. UV-Vis spectra were recorded using Perkin-Elmer Lambda 750 spectrophotometer. The Edinburg Life-Spec-II spectrophotometer (Laser source $375 \mathrm{~nm}$ ) was used for measurement of luminescence lifetimes. TEM (transmission electron microscope) images, HRTEM (high resolution transmission electron microscope) images and SAED (selected area electron diffraction) patterns were acquired using JEOL-JEM 2100 transmission electron microscope. Proton $\left(\mathrm{H}^{1}\right)$ and carbon $\left(\mathrm{C}^{13}\right)$ NMR (nuclear magnetic resonance) spectra were obtained using $600 \mathrm{MHz}$ Bruker ASCEND 600 nuclear magnetic resonance spectrometer. Electrospray ionization (ESI) mass spectrometric analyses were performed using Agilent Accurate Mass (LC/MS Q-TOF 6520) spectrometer in ESI positive mode.

2.3. Synthesis of $\mathrm{Zn}_{3}(\mathrm{AA})(\mathrm{OAc})_{2}$ nanoparticles: 
Zinc acetate dihydrate ( $200.0 \mathrm{mg})$ was dissolved in $10.0 \mathrm{~mL}$ of Milli-Q water in a clean vial. Thereafter, the solution was added with $\sim 18.0 \mathrm{mg}$ of ascorbic acid and the resultant mixture was stirred at room temperature $\left(\sim 25^{\circ} \mathrm{C}\right)$ for up to $36 \mathrm{~h}$.

\subsection{Photoluminescence and UV-vis absorbance study:}

$2.0 \mathrm{~mL}$ of aliquot of the resultant dispersion containing mixture of zinc acetate and ascorbic acid was taken in a quartz fluorescence cuvette. At intervals of $10 \mathrm{~min}$, the photoluminescence and UV-vis absorption spectra were acquired.

\subsection{TEM sample preparation:}

$10.0 \mu \mathrm{L}$ of the dispersion containing mixture of zinc acetate and ascorbic acid was diluted with $70 \mu \mathrm{L}$ Milli-Q water. $7.0 \mu \mathrm{L}$ of the resultant dispersion was drop cast on Formvarcarbon coated copper TEM grid and was allowed to dry overnight.

\subsection{Sample preparation for NMR analysis:}

In order to obtain the NMR spectra of the resultant product formed out of reaction between zinc acetate and ascorbic acid, requisite amounts of zinc acetate and ascorbic acid (as that in $\mathrm{H}_{2} \mathrm{O}$ ) were mixed in $\mathrm{D}_{2} \mathrm{O}$. The NMR spectra of $2.0 \mathrm{~mL}$ of the so obtained dispersions were acquired at various intervals of time.

\subsection{Purification of the luminescent product of reaction between ascorbic acid and zinc} acetate dihydrate:

The luminescent dispersion of the product of reaction between ascorbic acid and zinc acetate dihydrate was centrifuged at $24000 \mathrm{rpm}$ at $10{ }^{\circ} \mathrm{C}$ for $15 \mathrm{~min}$. The so obtained pellet was redispersed in water or other solvent and was used for further experiments.

\subsection{Sample preparation for ESI- Mass spectrometric analysis:}

The purified luminescent product was dissolved in methanol (HPLC grade) and mass spectra of the samples were acquired in ESI positive mode.

\subsection{Simulation of mass spectra:}

Mass spectra simulation was performed using mMass software. 


\section{Results and discussion:}

Addition of zinc acetate to an aqueous solution of ascorbic acid led to formation of a colorless dispersion. Initially, the absorbance spectrum of the dispersion did not consist of any discernible peak in the range of spectral acquisition (325 nm to $450 \mathrm{~nm}$ ). However, with time, the UV-vis absorbance of the reaction mixture increased with the emergence of a peak centred at $380 \mathrm{~nm}$ (Figure $1 \mathrm{~A}$ ). This indicated possible formation of an additional chemical species (reaction product or intermediate) in the medium. In order to establish that zinc acetate and ascorbic acid underwent chemical reaction, time - dependant UV-vis absorbance spectra of ascorbic acid as well as zinc acetate were acquired separately as control experiments (Figure S1 A-B). Interestingly, no significant peak appeared with time in the absorbance of zinc acetate. In an allied vein, no significant variation in the absorption characteristics of ascorbic acid was observed in absence of zinc acetate. The results indicated that zinc acetate and ascorbic acid reacted in the medium and a new species with absorbance in the UV-vis region was formed as a result.

In the next step, the photoluminescence emission and excitation spectra of the dispersion containing ascorbic acid and zinc acetate dihydrate were recorded. Interestingly, it was observed that the emergence of the absorbance peak of the reaction mixture at $380 \mathrm{~nm}$ was accompanied with photoluminescence (Figure $1 \mathrm{~B}$ ). Further, the reaction mixture at the initial period following mixing $(0-10 \mathrm{~min})$ was weakly emissive with an emission peak at $449 \mathrm{~nm}$. However, with the progress of time, the luminescence of the mixture increased significantly with simultaneous bathochromic shift of the emission maximum from $449 \mathrm{~nm}$ to $471 \mathrm{~nm}$ (Figure S2). In an allied vein, the excitation spectra of the reaction mixture recorded at regular intervals of time, also showed growth of a peak centered at $371 \mathrm{~nm}$, with the emission wavelength being set at the corresponding maxima (Figure $1 \mathrm{C}$ ). It was further observed that the shift in the emission maximum was observed till $\sim 45$ min after mixing the precursors and the intensity continued to increases till $\sim 36 \mathrm{~h}$. It is important to mention here that the optimum concentration of zinc acetate required for the best possible optical properties of the product was decided following several trials. For example, a fixed concentration of ascorbic acid ( $\sim 18 \mathrm{mg}$ in $10 \mathrm{~mL}$ water) was reacted with $20 \mathrm{mg}, 100 \mathrm{mg}$ or $200 \mathrm{mg}$ of zinc acetate. The time dependant luminescence spectra corresponding to each concentration of zinc acetate were then acquired (Figure S3). As is evident from Figure S3, the maximum luminescence at $\sim 36 \mathrm{~h}$ (depending on the rate of reaction) was observed when 
$\sim 200 \mathrm{mg}$ of zinc acetate - in comparison to dispersion containing other concentrations - was reacted with $\sim 18 \mathrm{mg}$ of ascorbic acid in $10 \mathrm{~mL}$ water. Further, we have monitored the reaction between $\sim 300 \mathrm{mg}$ of zinc acetate dihydrate and ascorbic acid (as above). Importantly, the trend of enhancement in luminescence of ascorbic acid with concomitant bathochromic shift, akin to the case of $200 \mathrm{mg}$ of zinc acetate dihydrate, was observed here as well.

The initial low intensity emission peak of the reaction mixture may be attributed to the luminescence of ascorbic acid owing to the presence of $\pi$ conjugated moieties and heteroatoms. The emission could also originate from the product(s) of the reaction between ascorbic acid and zinc acetate in the medium. In order to verify the role and the presence of both zinc ions and ascorbic acid in the so formed luminescent product(s), control experiments were performed where the same amounts of ascorbic acid and zinc acetate were kept separately and their luminescence behaviours were studied. Importantly, no discernible change in the luminescence of either of zinc acetate and ascorbic acid was observed with time (Figure S4 A-B). In order to probe the involvement of zinc ions in the formation of product(s), time - dependent photoluminescence spectra of each of the mixtures of cobalt acetate and ascorbic acid, nickel acetate and ascorbic acid, and copper acetate with ascorbic acid were recorded (Figure S5). Interestingly, in absence of zinc ions, weak luminescence with no clear peak as above could be observed. Thus, the observed luminescence could stem from the product(s) of the reaction involving zinc, ascorbate and acetate ions. Importantly, the role of acetate ion as a component of the luminescent species was further supported by the results of the control experiments. For instance, time - dependant luminescence spectra of mixtures of zinc perchlorate with ascorbic acid and zinc chloride with ascorbic acid (Figure S6) indicated no significant alteration in luminescence of ascorbic acid (Figure S6), thereby highlighting the crucial role of acetate as a unit of the newly formed luminescent species. Further, to a mixture of zinc chloride and ascorbic acid, which apparently had weak luminescence, sodium acetate was added. Intriguingly, upon addition of sodium acetate the mixture exhibited significant enhancement in luminescence (as were evident from the emission and excitation spectra) with concomitant bathochromic shift in the emission spectrum, akin to that of the dispersion of zinc acetate and ascorbic acid (Figure S7). Thus, the notable enhancement in the emission intensity of the reaction system comprising of zinc acetate and ascorbic acid with associated red shift, indicated possible formation of species involving zinc, acetate and ascorbate ions. Furthermore, time -dependent enhancement of 
photoluminescence and simultaneous gradual bathochromic shift indicated possible formation of species the properties of which depend on its (their) dimensions. In other words, in the medium, the dimensions of the newly formed species might have changed with time, giving rise to evolving photoluminescence. Further, time - resolved photoluminescence (TRPL) analysis was performed on the samples in a manner similar to that of steady state luminescence and UV-vis absorbance studies (Figure 1 D). Notably, the luminescence lifetime of the system was observed to undergo a sequential decrease with time. For example, the life-time varied from $2.24 \mathrm{~ns}$ to $1.48 \mathrm{~ns}$ for samples representing $0 \mathrm{~min}$ and $67 \mathrm{~min}$, respectively. This could be attributed to the formation of luminescent species with lower luminescence lifetimes vis-à-vis ascorbic acid, as a consequence of reaction involving zinc, ascorbate and acetate ions. The results also indicated possible size/dimension dependence of the luminescence life time of the species so formed in the medium. 
(A)

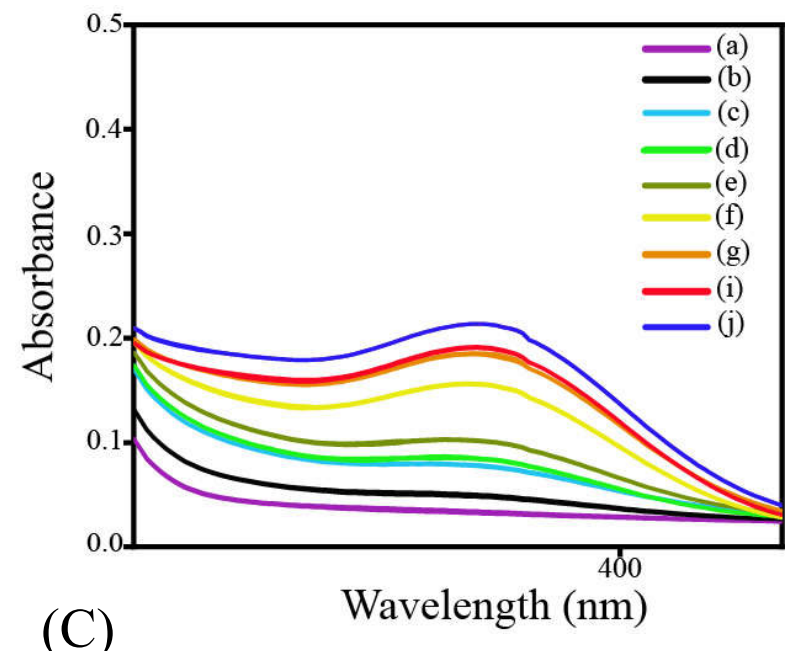

(C)

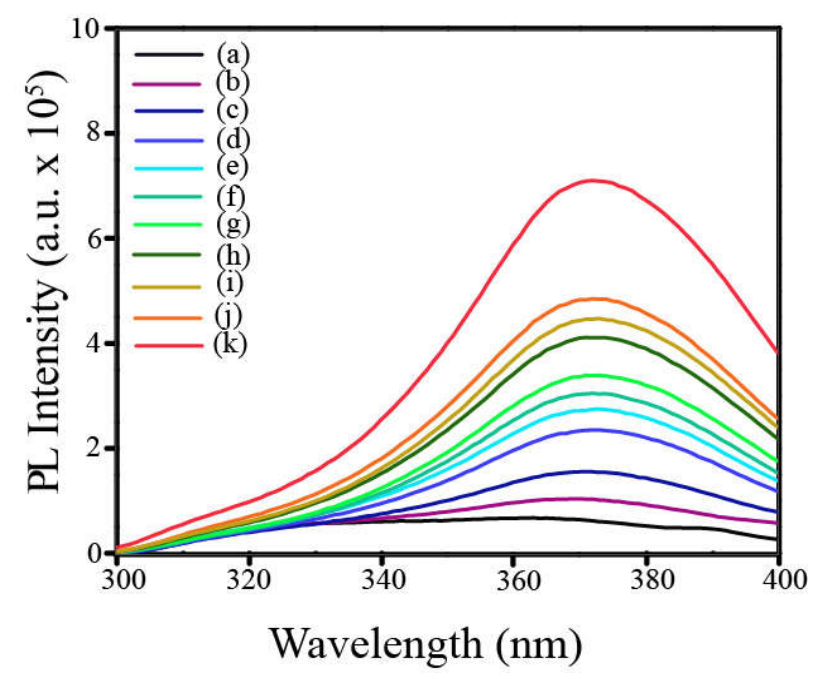

(B)
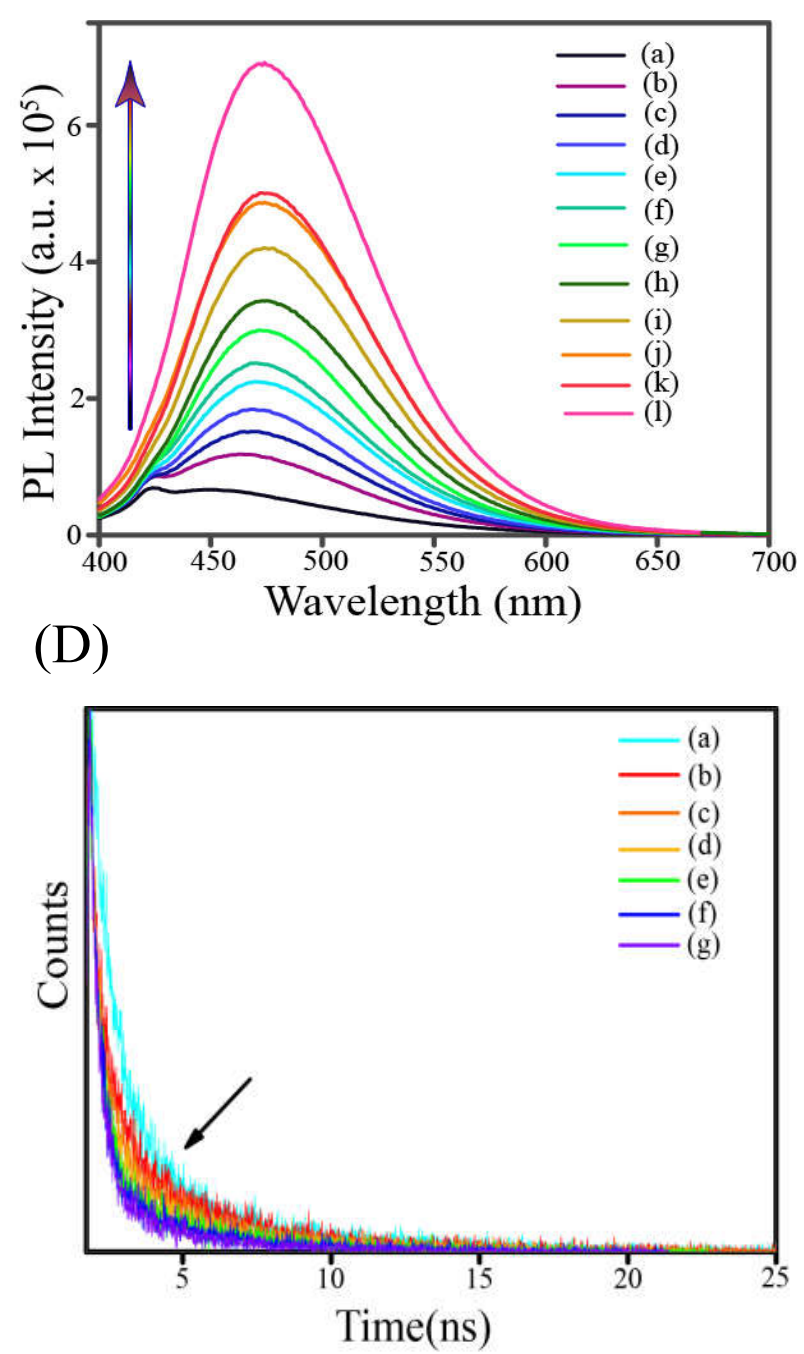

Figure 1 (A) UV-vis absorbance spectra of the reaction mixture comprising of ascorbic acid and zinc acetate dihydrate acquired at (a) $0 \mathrm{~min}$, (b) $20 \mathrm{~min}$, (c) $30 \mathrm{~min}$, (d) $40 \mathrm{~min}$, (e) 50 min, (f) $60 \mathrm{~min}$, (g) $130 \mathrm{~min}$, (h) $3 \mathrm{~h}$, (i) $4 \mathrm{~h}$ and (j) $5 \mathrm{~h}$ following mixing of ascorbic acid and zinc acetate dihydrate. (B) Luminescence spectra of the reaction mixture comprising of ascorbic acid and zinc acetate dihydrate acquired at (a) $0 \mathrm{~min}$, (b) $20 \mathrm{~min}$, (c) $30 \mathrm{~min}$, (d) 40 min, (e) $50 \mathrm{~min}$, (f) $60 \mathrm{~min}$, (g) $130 \mathrm{~min}$, (h) $3 \mathrm{~h}$, (i) $4 \mathrm{~h}$ and (j) $5 \mathrm{~h}$, (k) $6 \mathrm{~h} \mathrm{and} \mathrm{(l)} 18 \mathrm{~h}$ following mixing of ascorbic acid and zinc acetate dihydrate. (C) Luminescence excitation spectra of the reaction mixture comprising of ascorbic acid and zinc acetate dihydrate acquired at (a) $0 \mathrm{~min}$, (b) $20 \mathrm{~min}$, (c) $30 \mathrm{~min}$, (d) $40 \mathrm{~min}$, (e) $50 \mathrm{~min}$, (f) $60 \mathrm{~min}$, (g) $130 \mathrm{~min}$, (h) $3 \mathrm{~h}$, (i) $4 \mathrm{~h}$ and (j) $5 \mathrm{~h}$ and (k) $6 \mathrm{~h}$ following mixing of ascorbic acid and zinc acetate dihydrate. The excitation spectra were recorded following fixing of emission at the 
corresponding emission maximum. (D) Time resolved photoluminescence spectra of the reaction mixture comprising of ascorbic acid and zinc acetate dihydrate acquired at (a) 0 min, (b) $17 \mathrm{~min}$, (c) $27 \mathrm{~min}$, (d) $37 \mathrm{~min}$, (e) $47 \mathrm{~min}$, (f) $57 \mathrm{~min}$ and (g) $67 \mathrm{~min}$ following mixing of ascorbic acid and zinc acetate dihydrate.

Further, TEM analysis was performed to affirm the formation of nanoparticulate zinc complex. As evinced by TEM analysis, the augmented luminescence of the reaction mixture comprising of $\mathrm{Zn}$ acetate and ascorbic acid was attributed to the formation of crystalline spherical nanoparticles (Figure 2 A1-A4). Further, the time - dependant red shift observed in the luminescence of the reaction mixture provided an indication of gradual evolution of particle size. In order to confirm that, TEM analysis of the reaction mixture collected at regular intervals of time was performed. The results (Figure 2) indicated that the initial reaction mixture $(0 \mathrm{~h})$ showed the presence of featureless particle like images with no clear contrast (Figure 2 B). In other words, at the beginning, formation of nanoscale particles was not clearly observed. However, that had changed with time (Figure $2 \mathrm{C}-\mathrm{E}$ ). For instance, after $40 \mathrm{~min}$ of reaction, smaller particles with sizes up to $4 \mathrm{~nm}$ could be observed (Figure $2 \mathrm{~F} 1$ ). With further progress of the reaction - say at $6 \mathrm{~h}$ - larger particles (majority) in the size range of 12 to $16 \mathrm{~nm}$ (Figure $2 \mathrm{~F} 2$ ) were observed. Finally, after $24 \mathrm{~h}$ of reaction, TEM images of the so formed product revealed the presence of even larger particles with sizes up to $48 \mathrm{~nm}$ (Figure 2 F3). Thus, gradual enhancement of luminescence of the product of reaction between ascorbic acid and zinc acetate could be attributed to the formation of nanoscale particles with increasing size, as a function of time of reaction. Also, since the concomitant presence of zinc ions, acetate ions and ascorbate ions were indispensable for observation of the emergent nanoscale optical properties, the composition of the so formed nanoparticles was likely to involve all the aforementioned chemical species. Interestingly, the nanoparticulate species observed in TEM were found to be polycrystalline in nature. This is clear from the selected area electron diffraction images as reported in the insets of Figure 2 A3 and E3. 

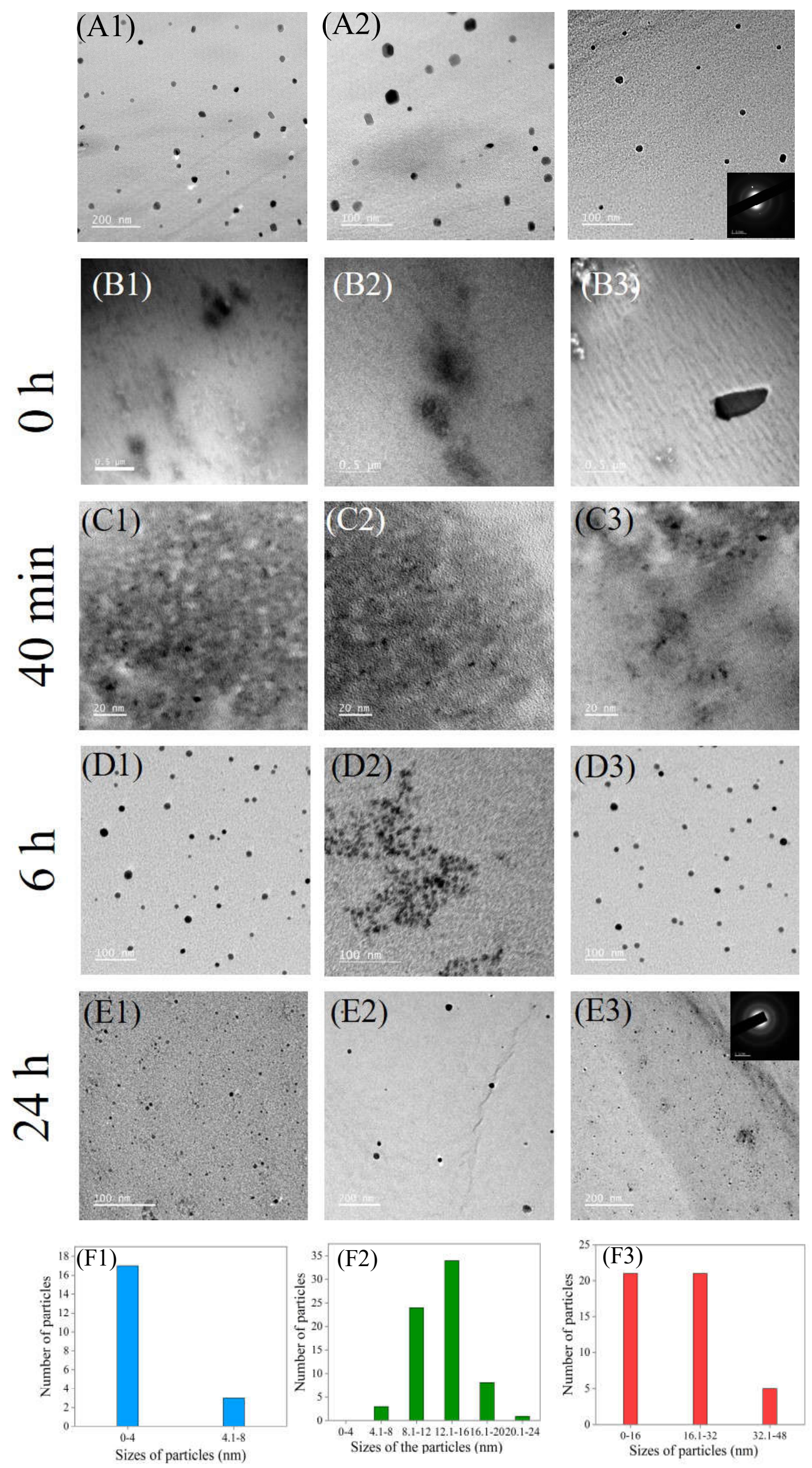
Figure 2. (A1-A3) Transmission electron microscopic images of the product of reaction between zinc acetate dihydrate and ascorbic acid acquired over various regions of the TEM grid. (A4) Selected area electron diffraction pattern acquired on a typical particle shown in (A1-A3). (B1-B3) Transmission electron microscopic images of the reaction mixture comprising of zinc acetate dihydrate and ascorbic acid drop cast on the TEM grid at $0 \mathrm{~h}$. (C1-C3) Transmission electron microscopic images of the reaction mixture comprising of zinc acetate dihydrate and ascorbic acid drop cast on the TEM grid at $30 \mathrm{~min}$. (D1-D3) Transmission electron microscopic images of the reaction mixture comprising of zinc acetate dihydrate and ascorbic acid drop cast on the TEM grid at $6 \mathrm{~h}$. (E1-E3) Transmission electron microscopic images of the reaction mixture comprising of zinc acetate dihydrate and ascorbic acid drop cast on the TEM grid at $24 \mathrm{~h}$ following mixing of zinc acetate dihydrate and ascorbic acid. Corresponding size distribution of nanoparticles collected at (F1) $40 \mathrm{~min}$, (F2) $6 \mathrm{~h}$ and (F3) $24 \mathrm{~h}$ of reaction between zinc acetate dihydrate and ascorbic acid.

Next, we were interested in identifying the chemical composition of the luminescent nanoparticulate species. In this regard, firstly, mass spectrometric analysis of the luminescent dispersion was pursued. As is evident from Figure 4 A-B, a peak at 510.8177, corresponding to the presence of $\mathrm{Zn}_{3}(\mathrm{AA})(\mathrm{OAc})_{2}$, was observed. The experimental mass spectra (isotopic abundance ratio) of the luminescent samples were found to be in agreement with the simulated mass spectra of $\mathrm{Zn}_{3}(\mathrm{AA})(\mathrm{OAc})_{2}+\mathrm{Na}^{+}$(Figure $\left.4 \mathrm{~A}-\mathrm{B}\right)$. Interestingly, the mass corresponding to the presence of $\mathrm{Zn}_{3}(\mathrm{AA})(\mathrm{OAc})_{2}$ was calculated to be 510.8147 which was in perfect agreement with the observed mass of 510.8177. Further, additional mases, consistent with the proposed structure of $\mathrm{Zn}_{\mathrm{x}}(\mathrm{AA})_{\mathrm{y}}(\mathrm{OAc})_{\mathrm{z}}$ were also obtained (Figure S8). Also, the various observed and simulated masses of $\mathrm{Zn}_{\mathrm{x}}(\mathrm{AA})_{\mathrm{y}}(\mathrm{OAc})_{\mathrm{z}}$ have been given in the SI, in tabulated form (Table S1). The observed masses are consistent with the proposed structure. The results thus substantiated the critical roles of both $\mathrm{Zn}^{2+}$ and acetate ions (in addition to ascorbate) in the luminescence of the new species. It is to be noted here that analogous complexes of ascorbate ions with platinum are well established in the literature. Further, complexes of platinum with ascorbate ions are known to exist in multiple stoichiometric ratios. For instance, reaction between platinum salt, alkyl diamine and ascorbic acid is known to give a mixture of products with composition such as [ $\mathrm{Pt}($ cis-amine $)($ ascorbate $)] \cdot 3 \mathrm{H}_{2} \mathrm{O}$ as well as $\left[\mathrm{Pt}(\text { cis-amine)(ascorbate })_{2} \cdot 2 \mathrm{H}_{2} \mathrm{O} \cdot{ }^{37}\right.$ Antitumor properties of such complexes have also been demonstrated. Further, the detailed mechanism of formation of platinum ascorbate 
complexes has been also been established in the literature. Thus, the formation of a complex of $\mathrm{Zn}^{2+}$ ion with ascorbate and acetate is consistent with the literature. 
(A)

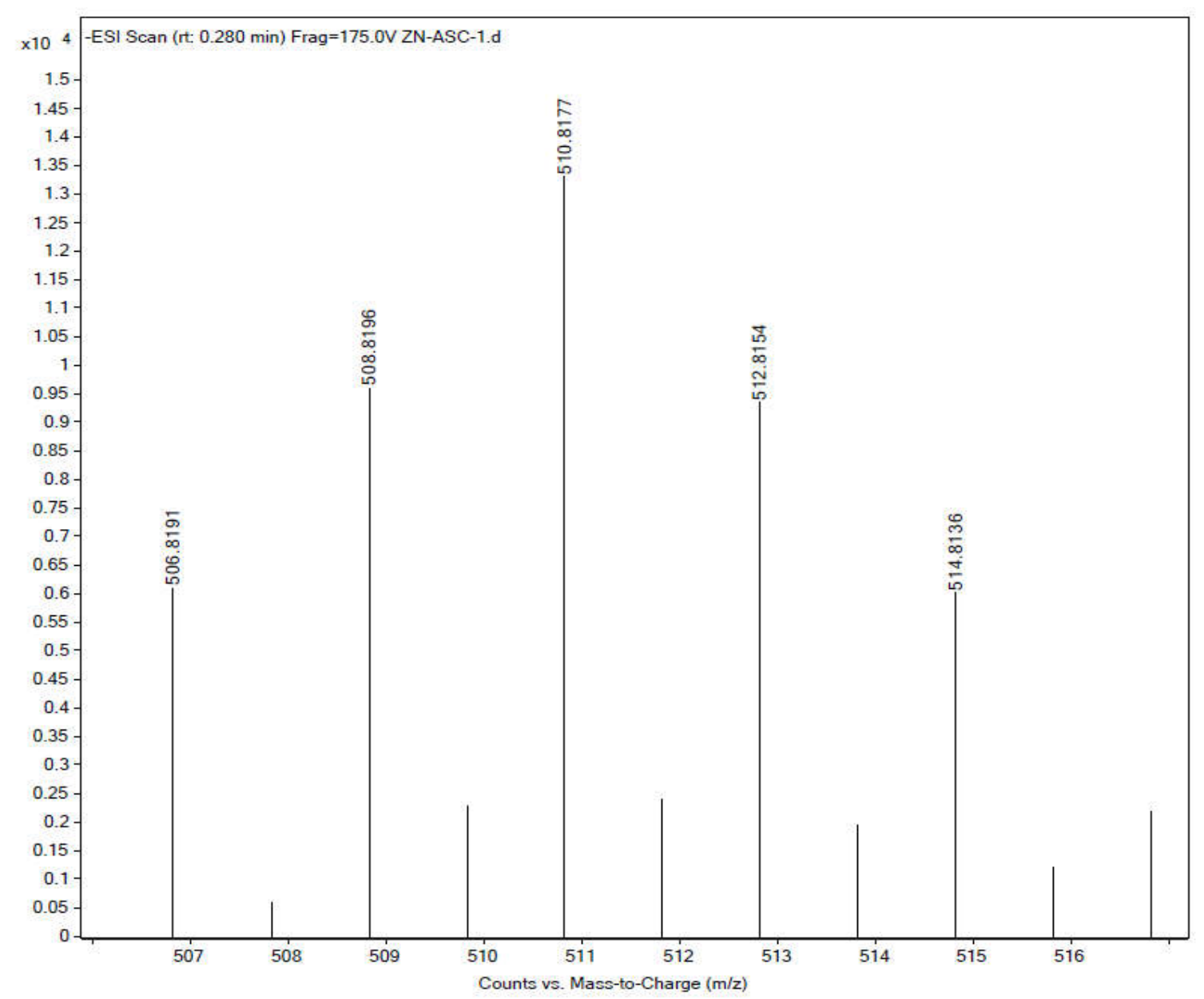

(B)

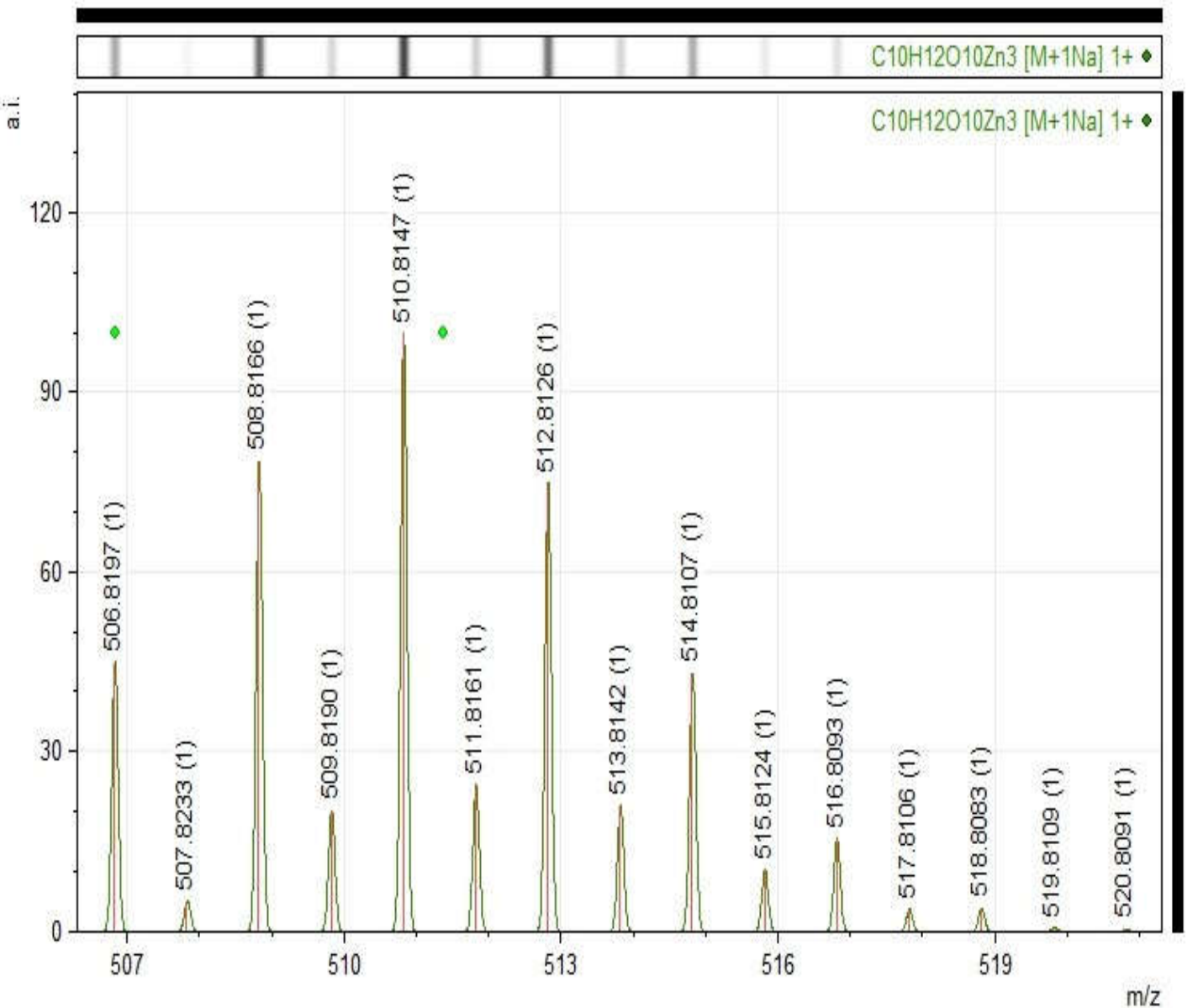


Figure 4. (A) Experimental mass spectrum of the luminescent dispersion indicating presence of $\mathrm{Zn}_{3}(\mathrm{AA})(\mathrm{OAc})_{2}$. (B) Simulated mass spectrum of $\mathrm{Zn}_{3}(\mathrm{AA})(\mathrm{OAc})_{2}$.

Further, NMR spectra of the mixture containing zinc acetate dihydrate and ascorbic acid in $\mathrm{D}_{2} \mathrm{O}$ were acquired. The observed chemical shifts of the protons of the resultant species were nearly concordant with the reported chemical shifts of the protons of zinc ascorbate (Figure 5). ${ }^{39}$ For example, the protons marked as $\left(\mathrm{H}_{\mathrm{c}}, \mathrm{H}_{\mathrm{d}}\right)$ and $\mathrm{H}_{\mathrm{b}}$ appeared at $\delta$ values of 3.56 and 3.84, respectively; whereas the literature reports of the $\delta$ values of these protons (corresponding to zinc ascorbate) are at 3.65-3.70 and 3.97, respectively, with similar splitting patterns. ${ }^{39}$ It may be noted here that the geminal protons in ascorbic acid (c,d) are known to undergo second order splitting and hence appear as multiplets. ${ }^{40}$ In addition, the chemical environment of the methylene protons might have been altered upon complexation reaction between adjacent hydroxyl groups and zinc ions. This might have led to further geminal splitting (doublet of doublet) of the peak centred at $3.84 \mathrm{ppm}$. Further, the peak corresponding to $3.56 \mathrm{ppm}$ appeared as a clear doublet of doublets of doublets as a consequence of vicinal coupling of two non-equivalent methylene protons. The results supported the reaction induced modification of the chemical environment around the abovementioned protons. This clearly indicated the variation in chemical environment of protons of ascorbic acid and acetate, which is a typical signature of complexation reaction. ${ }^{41}$ Further, the proton of zinc ascorbate, marked herein as $\mathrm{H} 3$, was observed to appear at a $\delta$ value of 4.35, which did match well with the reported value of 4.48 (Figure $5 \mathrm{D}$ ). The peak centred at $4.35 \mathrm{ppm}$ appeared as a doublet due to first order geminal coupling. In addition, the peaks due to the protons of acetate group were observed to be remarkably shifted vis-à-vis the peak due to protons of zinc acetate peak (1.75); (Figure S9). This also confirmed the role of acetate as a constituent of the luminescent zinc ascorbate complex formed as a product of the reaction between zinc acetate and ascorbic acid. Chemical shifts of $\mathrm{Zn}_{3}(\mathrm{AA})(\mathrm{OAc})_{2}$ vis-àvis ascorbic acid and zinc acetate dehydrate have been shown in Figure S8 A- D. Thus the ESI-MS results in conjunction with NMR results suggested the presence of $\mathrm{Zn}_{3}(\mathrm{AA})(\mathrm{OAc})_{2}$ as the building block of the luminescent nanoparticles observed in the TEM images. The chemical shifts of the protons of ascorbic acid and acetate, upon for formation of $\mathrm{Zn}_{3}(\mathrm{AA})(\mathrm{OAc})_{2}$ has been given in the SI in tabulated form (Table S2). 

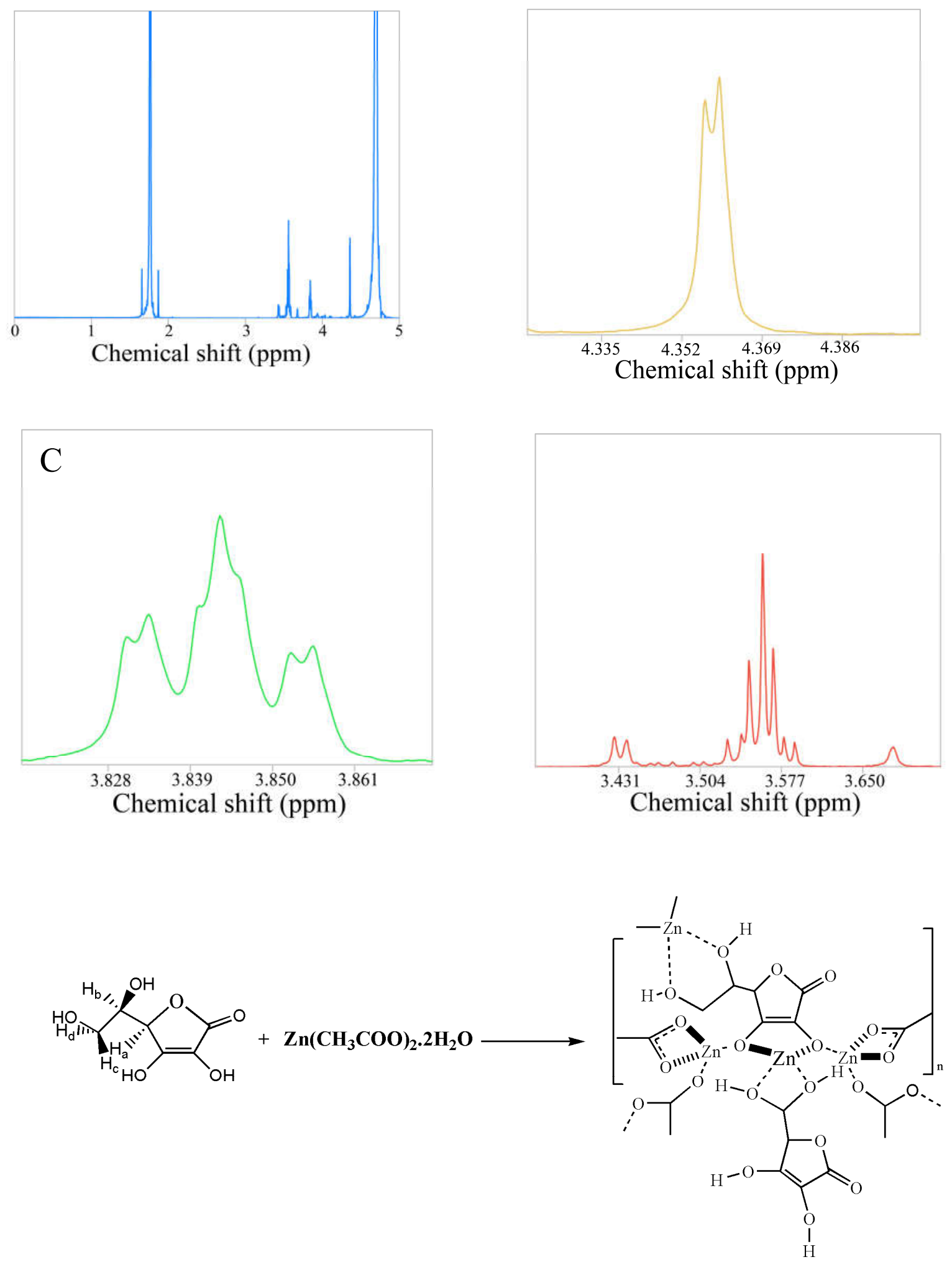

Figure 5. (A) NMR spectrum of $\mathrm{Zn}_{3}(\mathrm{AA})(\mathrm{OAc})_{2}$. (B) Magnified view of the peak shown in (A) at 4.35 for $\mathrm{H}_{\mathrm{a}}$. (C) Magnified view of the peak shown in (A) at 3.84 for $\mathrm{H}_{\mathrm{b}}$. (D) Magnified view of the peak shown in (A) at 3.56 for $\mathrm{H}_{\mathrm{c}}$ and $\mathrm{H}_{\mathrm{d}}$. A schematic representation 
of the nanoparticle formation out of reaction between ascorbic acid and zinc acetate dehydrate, $\mathrm{n}=$ any positive integer.

Moreover, Fourier transformed infrared (FTIR) spectroscopic analysis was performed to gain an insight into the plausible modes of bonding amongt zinc, acetate and ascorbate ions (Figure $\mathrm{S} 10)$. In the FTIR spectrum of $\mathrm{Zn}_{3}(\mathrm{AA})(\mathrm{OAc})_{2}$; the peak due to $\mathrm{C}=\mathrm{C}$ stretching frequency was observed at $1603 \mathrm{~cm}^{-1}$. Whereas, in case of ascorbic acid the $\mathrm{C}=\mathrm{C}$ stretching frequency was observed at $1664 \mathrm{~cm}^{-1}$. This could be due to the complexation of ascorbate with zinc. Notably, the peak due to $\mathrm{C}=\mathrm{O}$ in ascorbic acid was found to be absent in the FTIR spectrum of $\mathrm{Zn}_{3}(\mathrm{AA})(\mathrm{OAc})_{2}$, thereby indicating possible role of the carbonyl oxygen in hydrogen bonding leading to association of ascorbate moieties resulting in the formation of nanoparticles. Also, the peak due to $\mathrm{CH}_{2}$ in the FTIR spectrum of ascorbic acid $\left(1440 \mathrm{~cm}^{-1}\right)$ was observed to have undergone a shift of $56 \mathrm{~cm}^{-1}$ (to $1384 \mathrm{~cm}^{-1}$ ) upon formation of $\mathrm{Zn}_{3}(\mathrm{AA})(\mathrm{OAc})_{2}$. Importantly, the discrete peaks due to $\mathrm{OH}$ groups in ascorbic acid were found to have been altered into a broad peak at $3424 \mathrm{~cm}^{-1}$ in the FTIR spectrum of $\mathrm{Zn}_{3}(\mathrm{AA})(\mathrm{OAc})_{2}$ nanoparticles. This indicated possible coordination between zinc ions and the $\mathrm{OH}$ groups of ascorbic acid, leading to formation of nanoparticles.

Interestingly, the so formed nanoparticulate zinc complex of ascorbate and acetate, were found to exhibit excitation tuneable emission. As shown in Figure 4, upon gradually tuning of the excitation wavelength from 365 to $400 \mathrm{~nm}$, the emission maximum of the luminescent product (dispersion prepared following centrifugation and washing) shifted from $449 \mathrm{~nm}$ to $470 \mathrm{~nm}$. Notably, such excitation tuneable emissions have been reported for carbon dots, which have been explained based on the formation of surface defect states. On the other hand, nanoparticulate nature of the product may give rise to emission based on quantum confinement as in the case of quantum dots. This is further supported by the distribution of particle sizes as observed in the TEM images. Now it may be argued here that the origin of luminescence in the nanoparticulate species could be due to "aggregation induced emission" (AIE) of ascorbic acid. In order to probe this possibility, the emission spectra of the luminescent dispersion were acquired following serial dilutions. The results are reported in Figure S10. Thus, following sequential dilution, no significant change in the position of emission maximum was observed. Only, the luminescence intensity of the dispersion was observed to have decreased following dilution of the luminescent dispersion (Figure S11). In case of molecules leading to AIE, generally, the peak due to AIE is reported 
to disappear upon dilution. However, in the current study, no such alteration in the luminescence spectra of the species could be observed. Thus the emission characteristics observed herein were possibly due to the nanoscale particles of the complex formed out of $\mathrm{Zn}^{2+}$, acetate and ascorbate ions. That the nanoscale particles of such complex can lead to extraordinary emission - and the excitation wavelength tuneability of that - could also hold a clue to the emission characteristics of carbon dots.

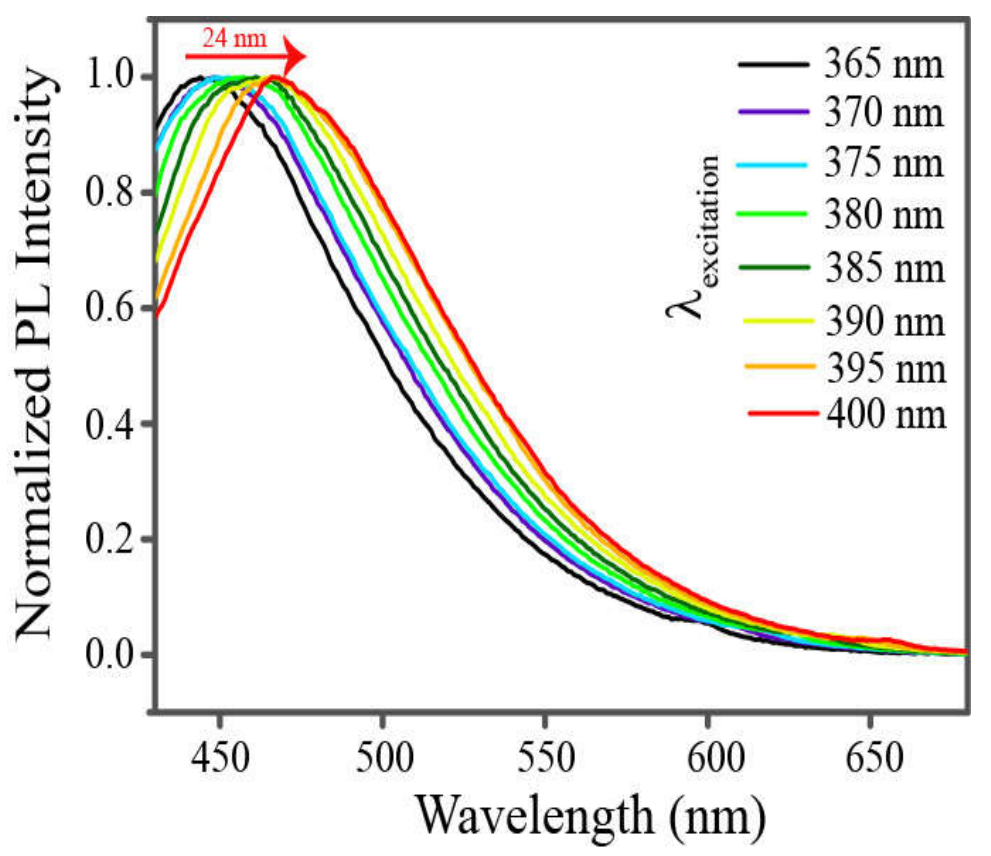

Figure 6. Normalized emission spectra of the product of reaction among $\mathrm{Zn}^{2+}$, acetate ions and ascorbate ions with varying excitation (wavelengths) as mentioned in the legends.

The results presented above suggest that an aqueous mixture of ascorbic acid and zinc acetate underwent chemical reaction leading to the formation of inorganic complexes with the formula $\mathrm{Zn}_{3}(\mathrm{AA})(\mathrm{OAc})_{2}$. The reaction between ascorbic acid and zinc acetate led to the formation of nanoparticles of varying sizes having an absorption peak at $371 \mathrm{~nm}$ and exhibiting excitation tunable photoluminescence. The nanoparticles so formed were constituted of $\mathrm{Zn}_{3}(\mathrm{AA})(\mathrm{OAc})_{2}$, as the building unit. Also, as evinced from FTIR analyses, hydrogen bonding might have played a prominent role in association of the $\mathrm{Zn}_{3}(\mathrm{AA})(\mathrm{OAc})_{2}$ units leading to the formation of complex nanoparticles. Although elucidating the exact origin of photoluminescence in the complex nanoparticles of $\mathrm{Zn}_{3}(\mathrm{AA})(\mathrm{OAc})_{2}$, is rather 
difficult and requires further investigation, as mentioned in earlier section, a possible mechanism of luminescence may be attributed to the contribution of the surface states. It could be that, akin to carbon dots, the $\mathrm{C}=\mathrm{O}$ functional groups present in the acetate moieties might have introduced newer energy levels (HOMO) and facilitated transition of electrons from HOMO-LUMO, decay of which could be probed based on emission in the visible wavelengths. Another possibility could be that, in line with quantum dots, the crystalline boundary of the weakly crystalline complexes of $\mathrm{Zn}_{3}(\mathrm{AA})(\mathrm{OAc})_{2}$, at the nanoscale, might have significantly governed the electron distribution of the nanocomplexes - known as quantum confinement effect - thereby leading to electronic transition of the complex nanoparticles in visible range. The presence of varied sizes in the medium might account for the wavelength tuneable emission. However, the exact mechanism of the photoluminescence is to be established through further works and evidences.

\section{Conclusion:}

In summary, we have developed a new luminescent nanoparticulate system comprising of $\mathrm{Zn}_{3}(\mathrm{AA})(\mathrm{OAc})_{2}$, as the building unit. We have shown for the first time that nanocrystals of inorganic complexes may also exhibit quantum behavior akin to other systems like quantum dots, atomic clusters and carbon dots. The process of nanoparticle formation upon reaction of zinc acetate dihydrate and ascorbic acid has been demonstrated using transmission electron microscopy. It was found that the size of the nanoparticles evolved with time. The nanoparticle formation was preceded by complexation reaction involving zinc, acetate and ascorbate ions. In addition, the control experiments indicated the importance of acetate ions in formation of luminescent nanoparticles. The so formed nanoparticles, similar to carbon dots, exhibited excitation tuneable emission. The composition of the building block of the so formed nanoparticles was substantiated by ESI-MS and NMR analyses and was found to be $\mathrm{Zn}_{3}(\mathrm{AA})(\mathrm{OAc})_{2}$. Experiments also suggested the critical role of the acetate ions in the complexation reaction followed by crystallization leading to emergence of new luminescent properties. The discovery of a new luminescent species based on nanoparticles of inorganic complexes provides an impetus to pursue further work in the field, which might provide interesting and important results. More importantly, the work portends to offer important anticipation with regard to emergence of new properties at the nanoscale on the way of crystallization of molecules as bulk precipitate. 


\section{References:}

1. D. A. Hanifi, N.D. Bronstein, B. E. Koscher, Z. Nett, J. K. Swabeck, K. Takano, A. M. Schwartzberg, L. Maserati, K. Vandewal, Y. V. D. Burgt, A. Salleo, A.P. Alivisatos, "Redefining near-unity luminescence in quantum dots with photothermal threshold quantum yield", Science, 2019, 363, 6432, 1199-1202.

2. S. Ye, A. P. Brown, A. C. Stammers, N. H. Thomson, J. Wen, L. Roach, R. J. Bushby, P. L. Coletta, K. Critchley, S. D. Connell, A. F. Markham, R. Brydson, S. D. Evans, "Sub-Nanometer Thick Gold Nanosheets as Highly Efficient Catalysts", Adv. Sci., 2019, 1900911.

3. Y. M. Su, Z. Wang, Q. Q. Zhao, X. P. Wang, C. H. Tung, D. Sun, "Unusual fcc-structured $\mathrm{Ag}_{10}$ kernels trapped in $\mathrm{Ag}_{70}$ nanoclusters", Chem. Sci., 2019, 10, 564-568.

4. R. Jin, C. Zeng, M. Zhou, Y. Chen, "Atomically Precise Colloidal Metal Nanoclusters and Nanoparticles: Fundamentals and Opportunities", Chem. Rev., 2016, 116, 18, 1034610413.

5. A. D. Kurdekar, L. A. A. Chundri, C. S. Manohar, M. K. Haleyurgirisetty, I. K. Hewlett, K. Venkataramaniah, "Streptavidin-conjugated gold nanoclusters as ultrasensitive fluorescent sensors for early diagnosis of HIV infection", Sci. Adv., 2018, 4,11, 6280.

6. L. Xiao, H. Sun, "Novel properties and applications of carbon nanodots", Nanoscale Horiz., 2018, 3, 565-597.

7. J. K. Lee, D. Samanta, H. G. Nam, R. N. Zare, "Spontaneous formation of gold nanostructures in aqueous microdroplets", Nat. Commun., 2018, 9, 1562.

8. Y. He, J. C. Liu, L Luo, Y. G. Wang, J Zhu, Y Du, J. Li, S. X. Lao, C. Wang, "Sizedependent dynamic structures of supported gold nanoparticles in $\mathrm{CO}$ oxidation reaction condition”, Proc. Natl. Acad. Sci. U.S.A., 2018, 115 (30) 7700-7705.

9. W. Zhou, X. Gao, D. Liu, X. Chen, "Gold Nanoparticles for In Vitro Diagnostics”, 2015, Chem. Rev., 115, 19, 10575-10636.

10. J. Song, Z. J. Zhang, S. S. Chen, T. Fan, L. Z. Gong, "Lewis Base/Copper Cooperatively Catalyzed Asymmetric $\alpha$-Amination of Esters with Diaziridinone", J. Am. Chem. Soc., 2018, 140, 9, 3177-3180.

11. J. H. Yoon, F. Selbach, L. Schumacher, J. Jose, S. Schüler, "Surface Plasmon Coupling in Dimers of Gold Nanoparticles: Experiment and Theory for Ideal (Spherical) and Nonideal (Faceted) Building Blocks", ACS Photonics, 2019, 6, 3, 642-648. 
12. M. K. Choi, J. Yang, T, Hyeon, D. H. Kim, "Flexible quantum dot light-emitting diodes for next-generation displays", npj Flexible Electronics, 2018, 2, 10.

13. Y. Jiang, S.Y. Cho, M. Shim, "Light-emitting diodes of colloidal quantum dots and nanorod heterostructures for future emissive displays”, J. Mater. Chem. C, 2018, 6, 2618-2634.

14. Y. Lu, Y. Yin, B. T. Mayers, Y. Xia, "Modifying the Surface Properties of Superparamagnetic Iron Oxide Nanoparticles through A Sol-Gel Approach", Nano Lett., 2002, 2, 3, 183-186.

15. H. L. Chee, C. R. R. Gan, M Ng, L Low, D. G. Fernig, K. K. Bhakoo, D. Paramelle, "Biocompatible Peptide-Coated Ultrasmall Superparamagnetic Iron Oxide Nanoparticles for In Vivo Contrast-Enhanced Magnetic Resonance Imaging”, ACS Nano, 2018, 12, 7 , 6480-6491.

16. K. L. Chen, M. Elimelech "Aggregation and Deposition Kinetics of Fullerene (C60) Nanoparticles" Langmuir, 2006, 22, 26, 10994-11001.

17. O. Zhou, H. Shimoda, B. Gao, S. Oh, L. Fleming, G. Yue, "Materials Science of Carbon Nanotubes: Fabrication, Integration, and Properties of Macroscopic Structures of Carbon", Nanotubes", Acc. Chem. Res., 2002, 35, 12, 1045-1053.

18. P. T. Yin, S. Shah, M. Chhowalla, K. B. Lee, "Design, Synthesis, and Characterization of Graphene-Nanoparticle Hybrid Materials for Bioapplications", Chem. Rev., 2015, 115, 7, 2483-2531.

19. T. Liu, Z. Liu, "2D $\mathrm{MoS}_{2}$ Nanostructures for Biomedical Applications”, Adv Healthc Mater., 2018, 7, 8, 1701158.

20. D. Lee, G. Monin, N.T. Duong, I. Z. Lopez, M. Bardet, V. Mareau, L. Gonon, G.D. Paëpe, "Untangling the Condensation Network of Organosiloxanes on Nanoparticles using 2D ${ }^{29} \mathrm{Si}-{ }^{29} \mathrm{Si}$ Solid-State NMR Enhanced by Dynamic Nuclear Polarization”, J. Am. Chem. Soc., 2014, 136, 39, 13781-13788.

21. G. Almeida, I. Infante, L. Manna, "Resurfacing halide perovskite nanocrystals", Science, 2019, 364, 6443, 833-834.

22. D. Yang, M. Cao, Q. Zhong, P. Li, X. Zhang, Q. Zhang, “All-inorganic cesium lead halide perovskite nanocrystals: synthesis, surface engineering and applications", J. Mater. Chem. C, 2019,7, 757-789.

23. Y. Dong, Y. Zhao, S. Zhao, Y. Dai, L. Liu, Y. Li, Q, Chen, "Recent advances toward practical use of halide perovskite nanocrystals", J. Mater. Chem. A, 2018,6, 21729-21746. 
24. W. Bae, S. Kocabey, T. Liedl, "DNA nanostructures in vitro, in vivo and on membranes", Nanotoday, 2019, 26, 98-107.

25. S. Huo, H. Li, A. J. Boersma, A. Herrmann, "DNA Nanotechnology Enters Cell Membranes", Adv Science, 2019, 6, 10.

26. N. Xie, S. Liu, H. Fang, Y. Yang, K. Quan, J. Li, X. Yang, K. Wang, J. Huang, “ ThreeDimensional Molecular Transfer from DNA Nanocages to Inner Gold Nanoparticle Surfaces", ACS Nano, 2019, 13, 4, 4174-4182.

27. J. M. Sanfrutos, M. Ortega-Munoz, J. Lopez-Jaramillo, F. Hernandez-Mateo, F. SantoyoGonzalez, "Synthesis of Molecular Nanocages by Click Chemistry", J. Org. Chem., 2008, $73,19,7772-7774$.

28. J. Yang, A. Bahreman, G. Daudey, J. Bussmann, R. C. L. Olsthoorn, A. Keos, "Drug Delivery via Cell Membrane Fusion Using Lipopeptide Modified Liposomes”, ACS Cent. Sci., 2016, 2, 9, 621-630.

29. A. K. Rengan, A. B. Bukhari, A. Pradhan, R. Malhotra, R. Banerjee, R. Srivastava, A. De, "In Vivo Analysis of Biodegradable Liposome Gold Nanoparticles as Efficient Agents for Photothermal Therapy of Cancer", Nano Lett.2015152842-848

30. G. A. Dichello, T. Fukuda, T. Maekwa, R. L. D. Whitby, S. V. Mikhalovsky, M. Alavijeh, A. S. Pannala, D. K. Sarker, "Preparation of liposomes containing small gold nanoparticles using electrostatic interactions", Eur. J. Pharm. Sci., 2017, 105, 55-63.

31. P. Sudhagar, T.P. Radhakrishnan, "Stimuli responsive and reversible crystalline-amorphous transformation in a molecular solid: fluorescence switching and enhanced phosphorescence in the amorphous state", J. Mater. Chem. C, 2019,7, 7083-7089.

32. S. Jayanty, T.P. Radhakrishnan, "Spontaneous Resolution through Helical Assembly of a Conformationally Chiral Molecule with an Unusual Zwitterionic Structure”, Chem.: Eur. $J ., 2004,10,11,2661-2667$

33. L. Zong, H. Zhang, Y. Li, Y. Gong, D. Li, J. Wang, Z. Wang, Y. Xie, M. Han, Q. Peng, X. Li, J. Dong, J. Qian, Q. Li, Z. Li, “Tunable Aggregation-Induced Emission Nanoparticles by Varying Isolation Groups in Perylene Diimide Derivatives and Application in Three-Photon Fluorescence Bioimaging”, ACS Nano, 2018, 12, 9, 95329540.

34. X. Feng, Z. Xu, C. Qi, D. Luo, X. Zhao, Z. Mu, C. Redshaw, J. W. Y. Lam, D. Ma, B. Z. Tang, "Pyrene-based blue emitters with aggregation-induced emission features for highperformance organic light-emitting diodes", J. Mater. Chem. C, 2019,7, 2283-2290. 
35. Z. Q. Cao, Q. Miao, Q. Zhang, H. Li, D.H. Qu, H. Tian, “A fluorescent bistable [2] rotaxane molecular switch on $\mathrm{SiO}_{2}$ nanoparticles", Chem. Commun., 2015, 51, 4973-4976.

36. G. G. Ramirez, D. A. Leigh, A. J. Stephens, "Catenanes: Fifty Years of Molecular Links”, Angew. Chem. Int. Ed, 2015, 54,21, 6110-6150.

37. L. S. Hollis, A. R. Amundsen, E. W. Stern," Synthesis, structure and antitumor properties of platinum complexes of vitamin C", J. Am. Chem. Soc., 1985,107, 1,274-276.

38. M. J. Arendse, G. K. Anderson, N. P. Rath, "Synthesis and Characterization of Platinum (II) Complexes of 1-Ascorbic Acid. Crystal Structure of Ascorbato- $C^{2}, O^{5}$ ethylenediamineplatinum(II) Dihydrate", Inorg. Chem., 1999, 38, 25, 5864-5869.

39. C. Unaleroglu, B. Zumreoglu, K. Y. Mert, "Zinc ascorbate: a combined experimental and computational study for structure elucidation", J Mol Struct, 2002, 605, 2-3, 227-233.

40. R. S. Reid, "The proton NMR spectrum of ascorbic acid: A relevant example of deceptively simple second-order behaviour", J. Chem. Educ., 1989, 66, 4, 344.

41. J. C. Ott, H. Wadepohl, M. Enders, L. H. Gade, "Taking Solution Proton NMR to Its Extreme: Prediction and Detection of a Hydride Resonance in an Intermediate-Spin Iron Complex", J. Am. Chem. Soc., 2018, 140, 50, 17413-17417.

\section{Acknowledgements:}

We thank the Department of Electronics and Information Technology, Government of India [Grant 5(9)/2012-NANO, Vol. III], for financial support. In addition, assistance from Central Instruments Facility, IIT Guwahati, is acknowledged.

\section{Conflicts of Interest:}

There are no conflicts to declare

\section{ORCID ID:}

Arun Chattopadhyay: 0000-0001-5095-6463 


\section{Ambient Complexation Reaction of Zinc Acetate and Ascorbic acid Leads to a New Form of Nanoscale Particles with Emergent Optical Properties}

Srestha Basua\$
Chattopadhyay ${ }^{\mathrm{a}, \mathrm{b}^{*}}$

\section{${ }^{\$}$ Equal Contribution}

${ }^{a}$ Department of Chemistry, Indian Institute of Technology Guwahati, Guwahati 781039, India

${ }^{\mathrm{b}}$ Centre for Nanotechnology, Indian Institute of Technology Guwahati,

Guwahati 781039, India

E-mail: $\underline{\text { arun@iitg.ac.in }}$

\section{Supporting Information}



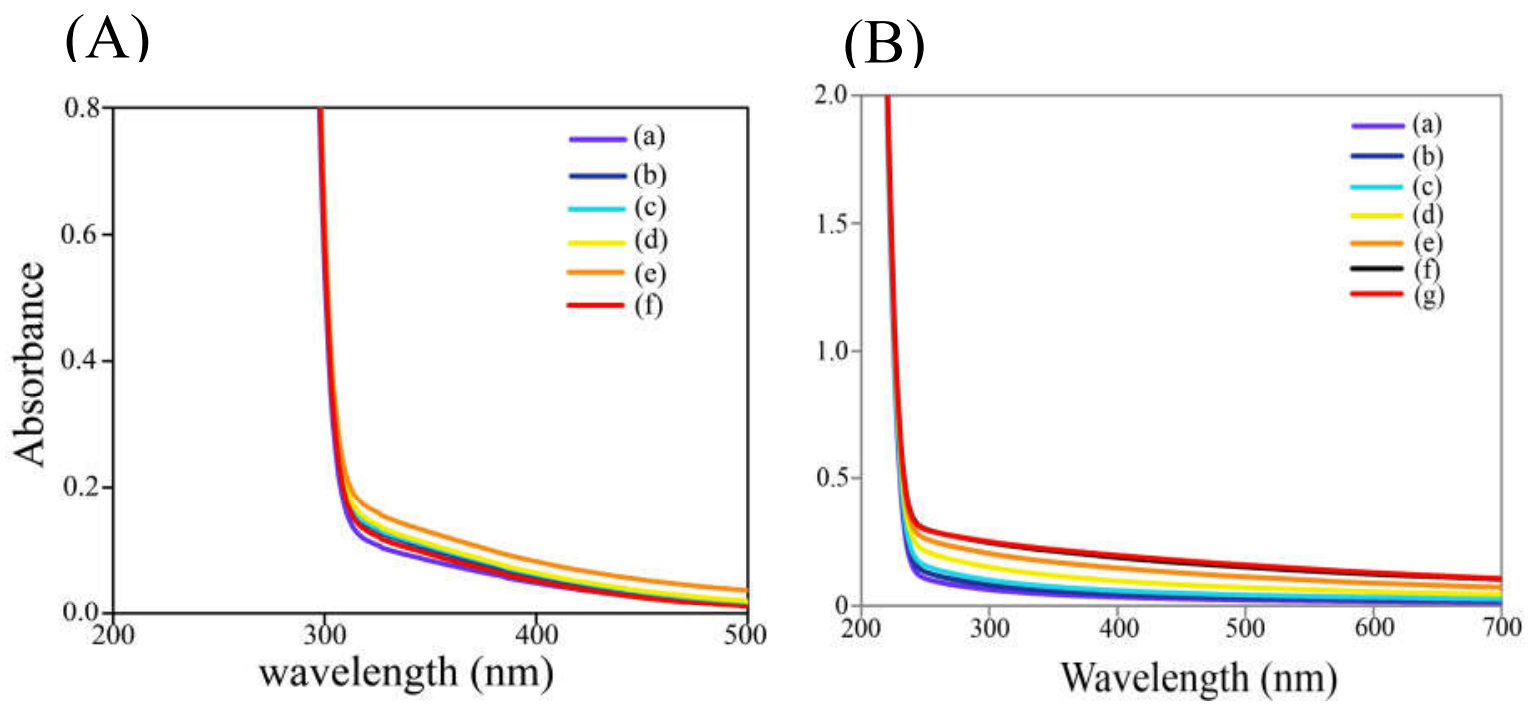

Figure S1 (A) UV-absorbance spectra of ascorbic acid acquired at (a) $0 \mathrm{~min}$, (b) $10 \mathrm{~min}$, (c) $20 \mathrm{~min}$, (d) $40 \mathrm{~min}$, (e) $50 \mathrm{~min}$, and (f) $60 \mathrm{~min}$. (B) UV-absorbance spectra of zinc acetate at (a) $0 \mathrm{~min}$, (b) $10 \mathrm{~min}$, (c) $20 \mathrm{~min}$, (d) $30 \mathrm{~min}$, (e) $40 \mathrm{~min}$, (f) $50 \mathrm{~min}$ and (g) $60 \mathrm{~min}$. Here 0 min refers to the time when zinc acetate and ascorbic acid were mixed.

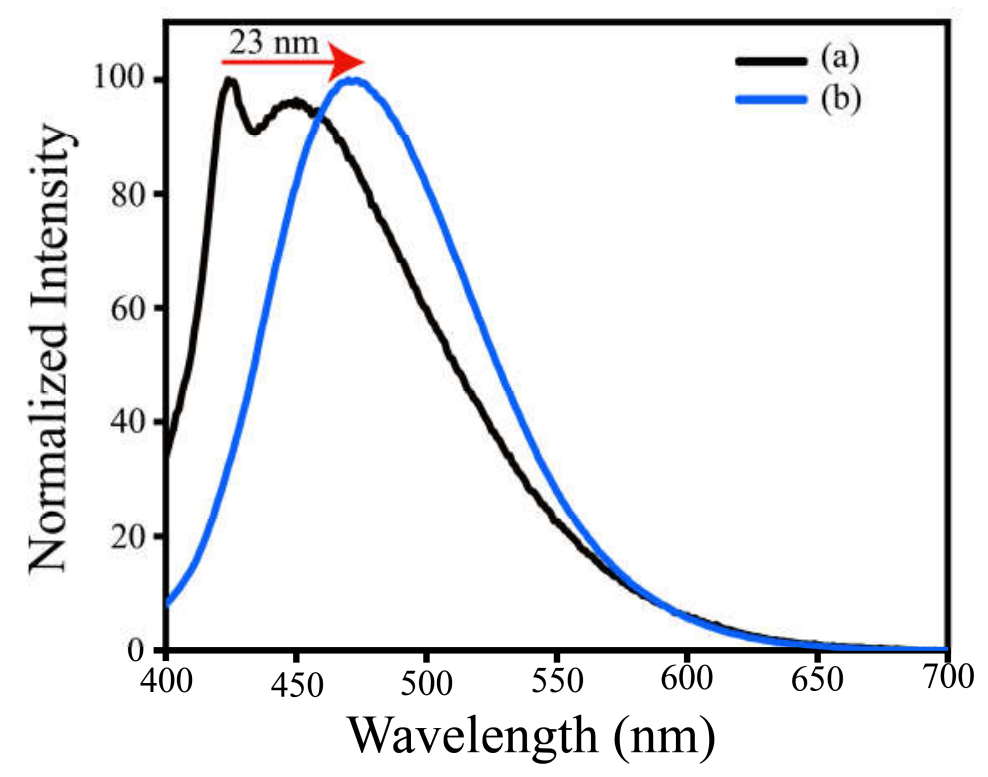

Figure S2. Normalized emission spectra of (a) ascorbic acid and (b) reaction mixture of zinc acetate dihydrate and ascorbic acid. The excitation wavelength was set at $371 \mathrm{~nm}$. 
(A)

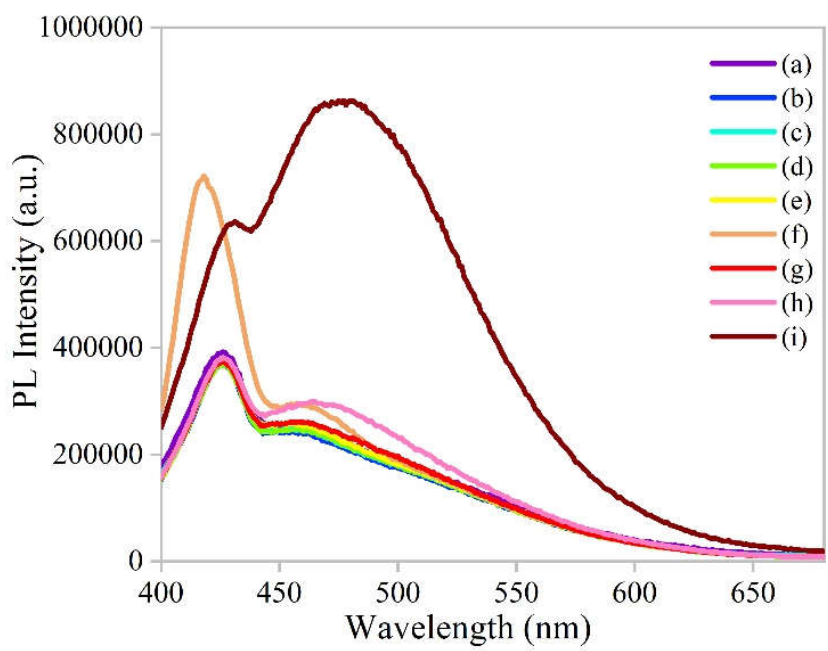

(C)

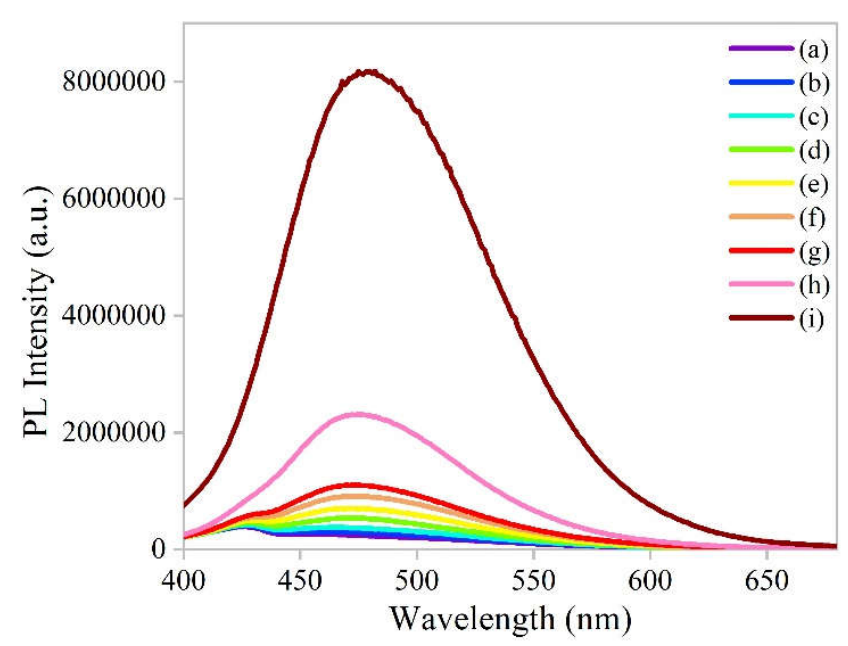

(B)

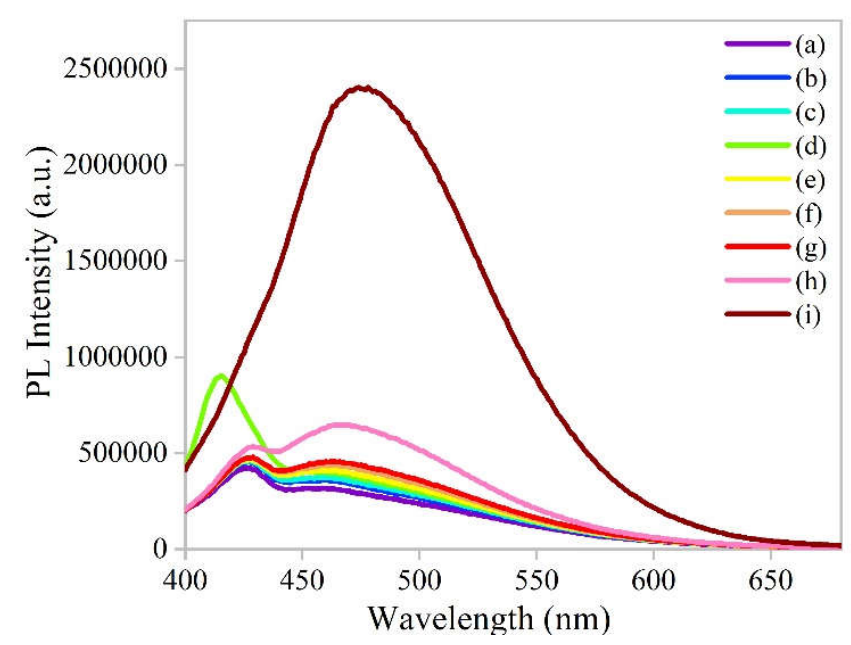

(D)

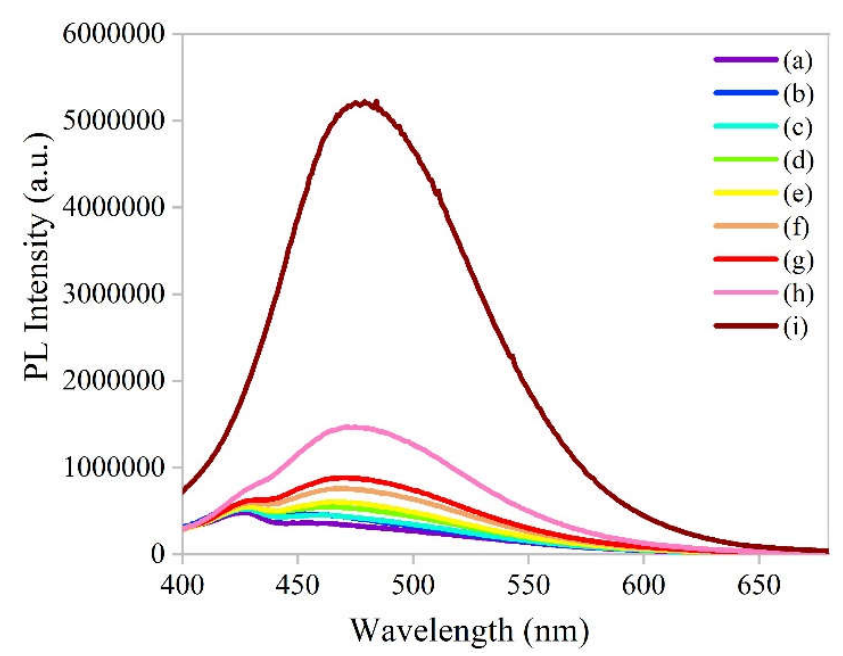

Figure S3. (A) Emission spectra of the reaction mixture containing ascorbic acid and $\sim 20$ mg zinc acetate at (a) $0 \mathrm{~min}$, (b) $10 \mathrm{~min}$, (c) $20 \mathrm{~min}$, (d) $30 \mathrm{~min}$, (e) $40 \mathrm{~min}$, (f) $50 \mathrm{~min}$, (g) 60 min, (h) $120 \mathrm{~min}$, and (i) $12 \mathrm{~h}$. (B) Emission spectra of the reaction mixture containing ascorbic acid and $~ 100 \mathrm{mg}$ zinc acetate at (a) $0 \mathrm{~min}$, (b) $10 \mathrm{~min}$, (c) $20 \mathrm{~min}$, (d) $30 \mathrm{~min}$, (e) $40 \mathrm{~min}$, (f) $50 \mathrm{~min}$, (g) $60 \mathrm{~min}$, (h) $120 \mathrm{~min}$, and (i) $12 \mathrm{~h}$. (C) Emission spectra of the reaction mixture containing ascorbic acid and $200 \mathrm{mg}$ zinc acetate at (a) $0 \mathrm{~min}$, (b) $10 \mathrm{~min}$, (c) 20 min, (d) $30 \mathrm{~min}$, (e) $40 \mathrm{~min}$, (f) $50 \mathrm{~min}$, (g) $60 \mathrm{~min}$, (h) $120 \mathrm{~min}$, and (i) 12 h. (D) Emission spectra of the reaction mixture containing ascorbic acid and $\sim 300 \mathrm{mg}$ zinc acetate at (a) 0 min, (b) 10min, (c) $20 \mathrm{~min}$, (d) $30 \mathrm{~min}$, (e) $40 \mathrm{~min}$, (f) $50 \mathrm{~min}$, (g) $60 \mathrm{~min}$, (h) $120 \mathrm{~min}$, and 
(i) $12 \mathrm{~h}$. The excitation wavelength was set at $371 \mathrm{~nm}$ Here 0 min refers to the time when zinc acetate and ascorbic acid were mixed.

(A)

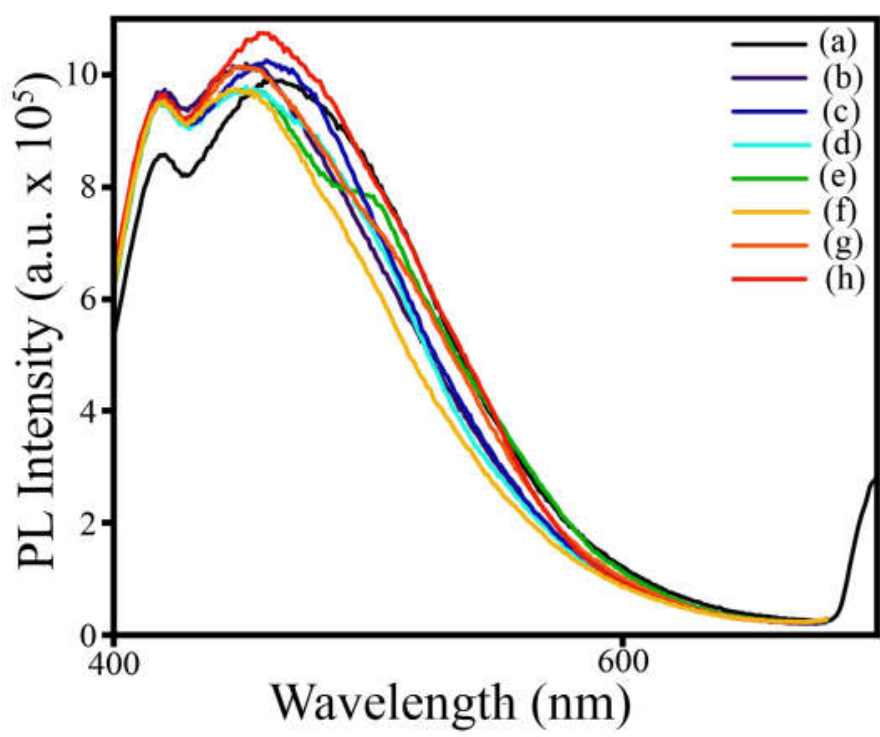

(B)

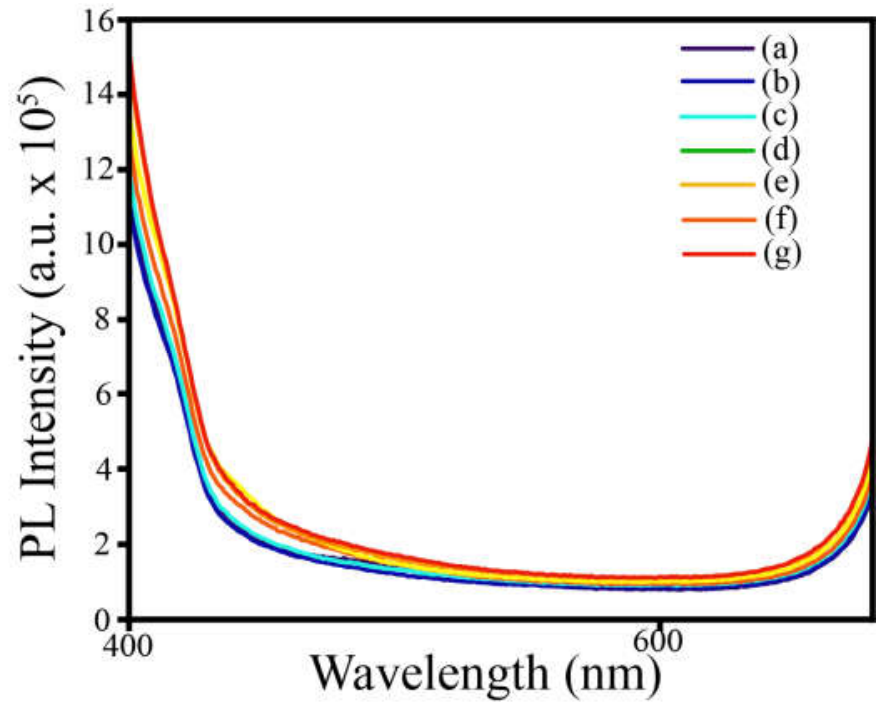

Figure S4 (A) Photoluminescence spectra of ascorbic acid acquired at (a) $0 \mathrm{~min}$, (b) $14 \mathrm{~min}$, (c) $22 \mathrm{~min}$, (d) $30 \mathrm{~min}$, (e) $40 \mathrm{~min}$, (f) $50 \mathrm{~min}$, (g) $60 \mathrm{~min}$ and (h) $120 \mathrm{~min}$.

Photoluminescence spectra of zinc acetate dihydrate acquired at (a) $0 \mathrm{~min}$, (b) $10 \mathrm{~min}$, (c) 20 min, (d) $30 \mathrm{~min}$, (e) $40 \mathrm{~min}$, (f) $50 \mathrm{~min}$ and (g) $60 \mathrm{~min}$. The excitation wavelength was set at $365 \mathrm{~nm}$. Here $0 \mathrm{~min}$ refers to the time when zinc acetate and ascorbic acid were mixed. 
(A)

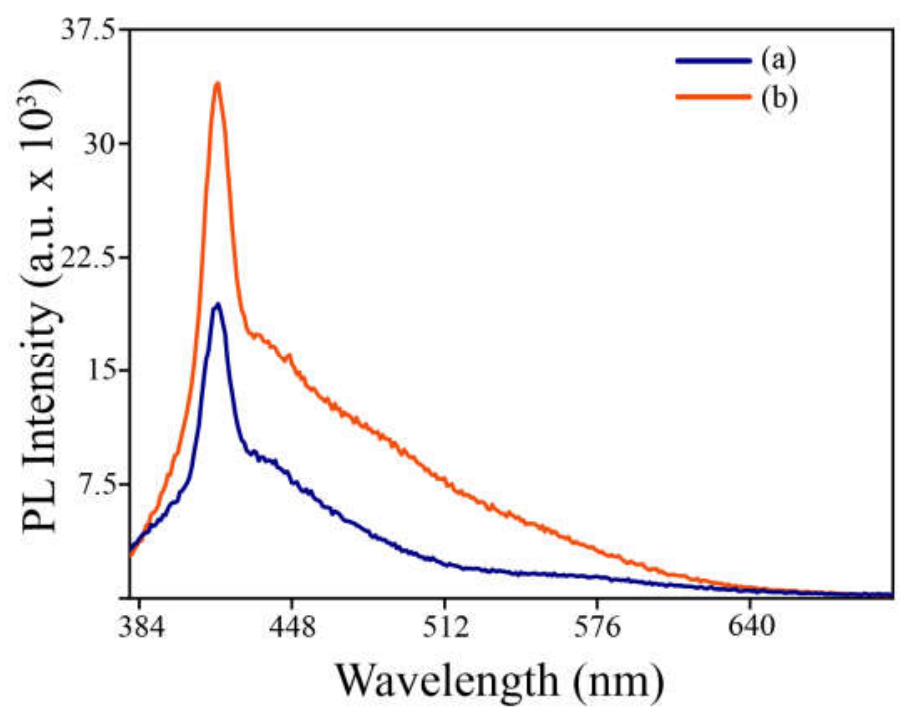

(B)

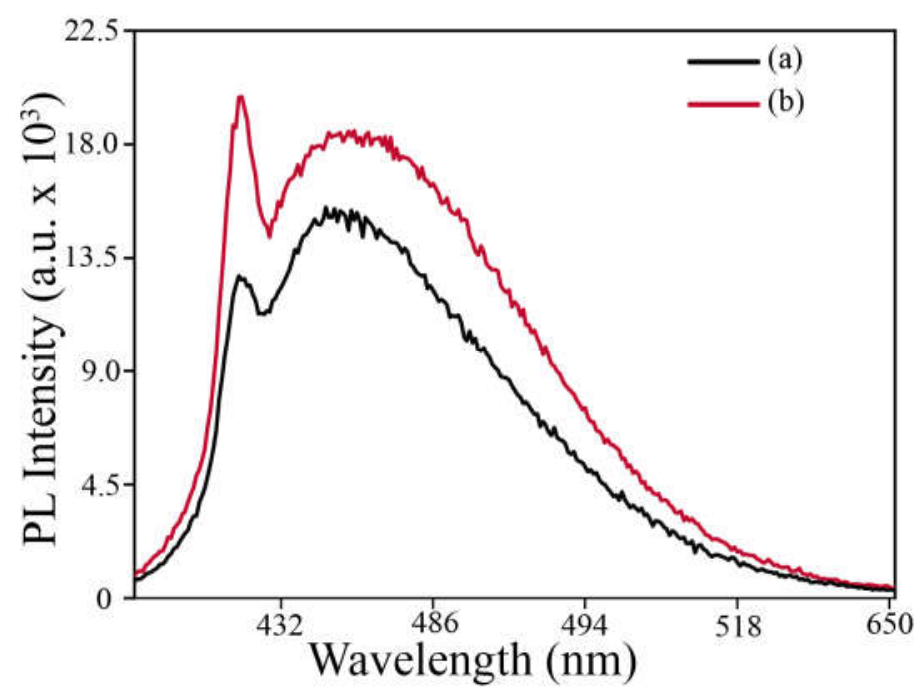

(C)

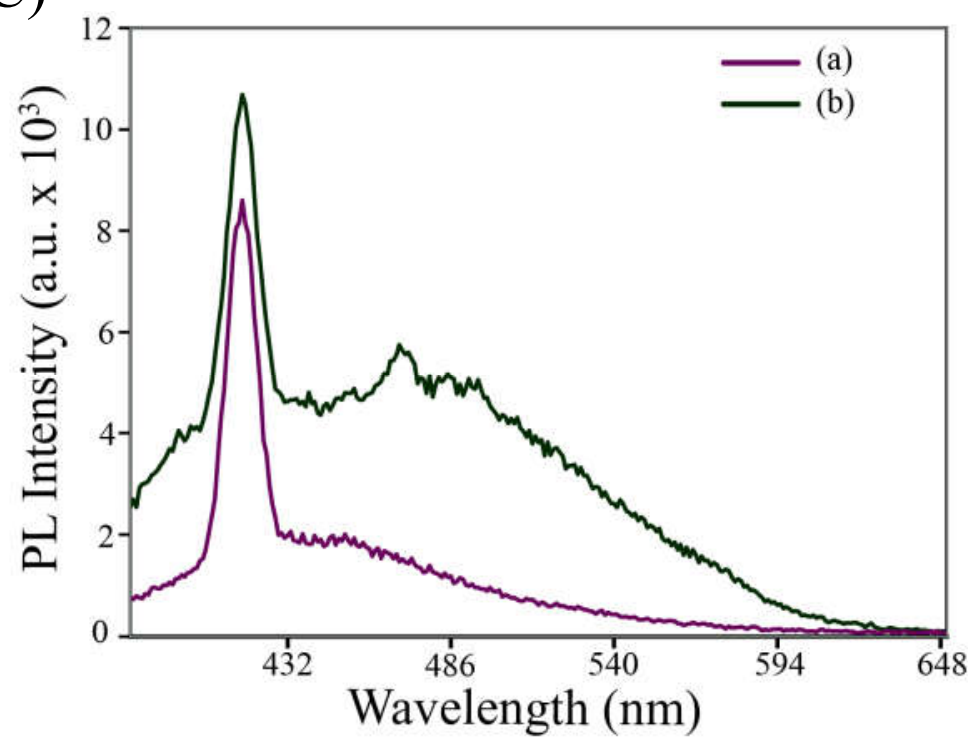

Figure S5 (A) Photoluminescence spectra of a mixture of $\sim 200 \mathrm{mg}$ of cobalt acetate and $18.0 \mathrm{mg}$ of ascorbic acid acquired at (a) $6 \mathrm{~h}$ and (b) $11 \mathrm{~h}$. (B) Photoluminescence spectra of a mixture of $\sim 200 \mathrm{mg}$ of nickel acetate and $\sim 18 \mathrm{mg}$ of ascorbic acid acquired at (a) $6 \mathrm{~h}$ and (b) $11 \mathrm{~h}$. (C) Photoluminescence spectra of a mixture of $\sim 200 \mathrm{mg}$ of copper acetate and $\sim 18 \mathrm{mg}$ of ascorbic acid acquired at (a) $6 \mathrm{~h}$ and (b) $11 \mathrm{~h}$. The excitation wavelength was set at 365 $\mathrm{nm}$. 

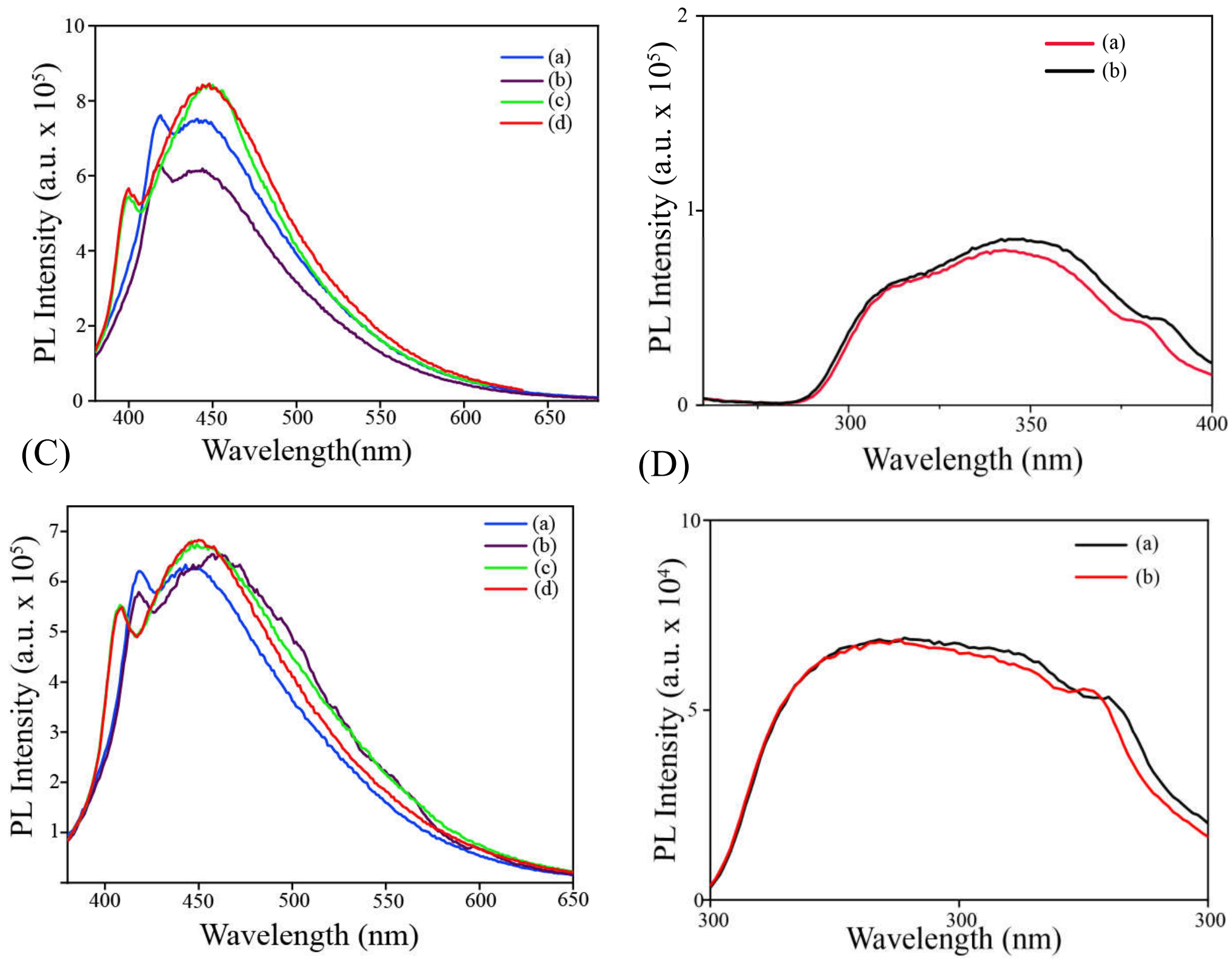

Figure S6 (A) Emission spectra of the reaction mixture containing $\sim 200 \mathrm{mg}$ of zinc perchlorate and $\sim 18.0 \mathrm{mg}$ of ascorbic acid acquired at (a) $1 \mathrm{~h}$, (b) $2 \mathrm{~h}$, (c) $3 \mathrm{~h}$ and (d) $8 \mathrm{~h}$. The excitation wavelength was set at $365 \mathrm{~nm}$. (B) Excitation spectra of the reaction mixture containing $\sim 200.0 \mathrm{mg}$ of zinc perchlorate and $\sim 18.0 \mathrm{mg}$ ascorbic acid acquired at (a) $3 \mathrm{~h}$ and (b) $8 \mathrm{~h}$. Emission wavelength was set at corresponding emission maxima. (C) Emission spectra of the reaction mixture containing $\sim 200 \mathrm{mg}$ zinc chloride and ascorbic acid acquired at (a) $1 \mathrm{~h}$, (b) $2 \mathrm{~h}$, (c) $3 \mathrm{~h}$ and (d) $8 \mathrm{~h}$. Excitation wavelength was set at $365 \mathrm{~nm}$. (D) Excitation spectra of the reaction mixture containing $\sim 200 \mathrm{mg}$ zinc chloride and ascorbic acid acquired at (a) $3 \mathrm{~h}$ and (b) $8 \mathrm{~h}$. Emission wavelength was set at corresponding emission maxima. 
(A)

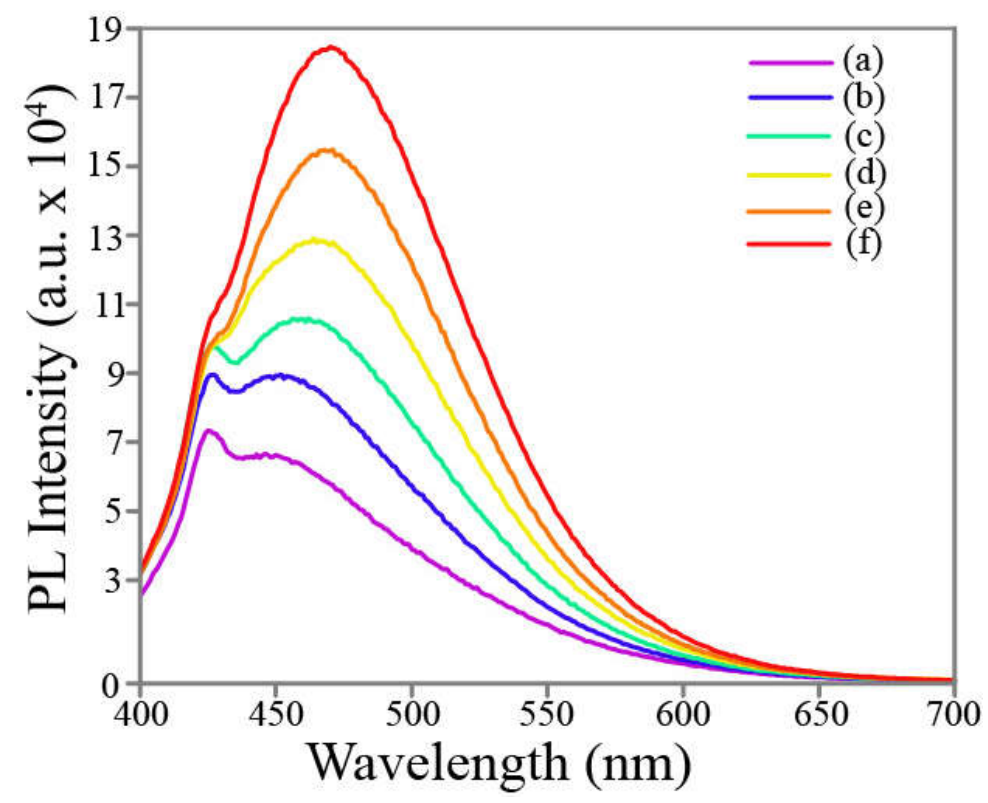

(B)

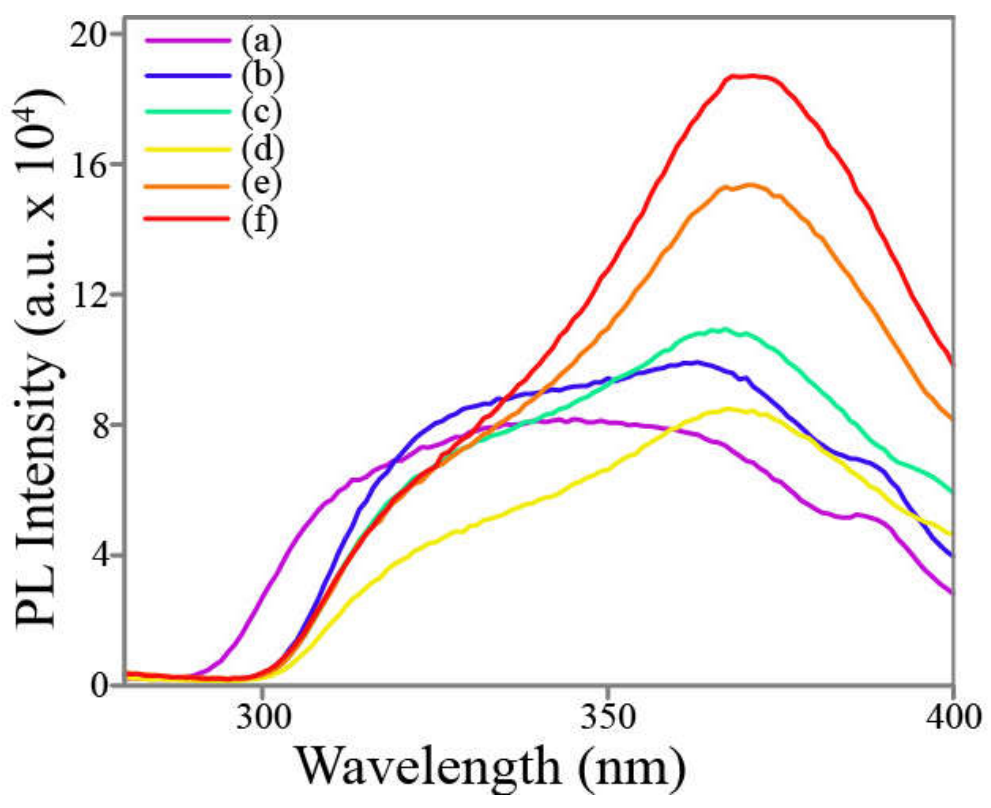

Figure S7 (A) Emission spectrum of a mixture of (a) $\sim 127 \mathrm{mg}$ of zinc chloride and $\sim 18.0$ $\mathrm{mg}$ of ascorbic acid and that following addition of $\sim 200 \mathrm{mg}$ sodium acetate and recorded after (b) $24 \mathrm{~min}$, (c) $60 \mathrm{~min}$, (d) $90 \mathrm{~min}$, (e) $142 \mathrm{~min}$ and (f) $180 \mathrm{~min}$; excitation wavelength was set at $371 \mathrm{~nm}$. (B) Excitation spectrum of a mixture of (a) $127 \mathrm{mg}$ of zinc chloride and $\sim 18.0 \mathrm{mg}$ of ascorbic acid and that following addition of $\sim 200 \mathrm{mg}$ sodium acetate and recorded after (b) $24 \mathrm{~min}$, (c) $60 \mathrm{~min}$, (d) $90 \mathrm{~min}$, (e) $142 \mathrm{~min}$ and (f) $180 \mathrm{~min}$. Emission wavelength was set at corresponding emission maxima. 
(A)

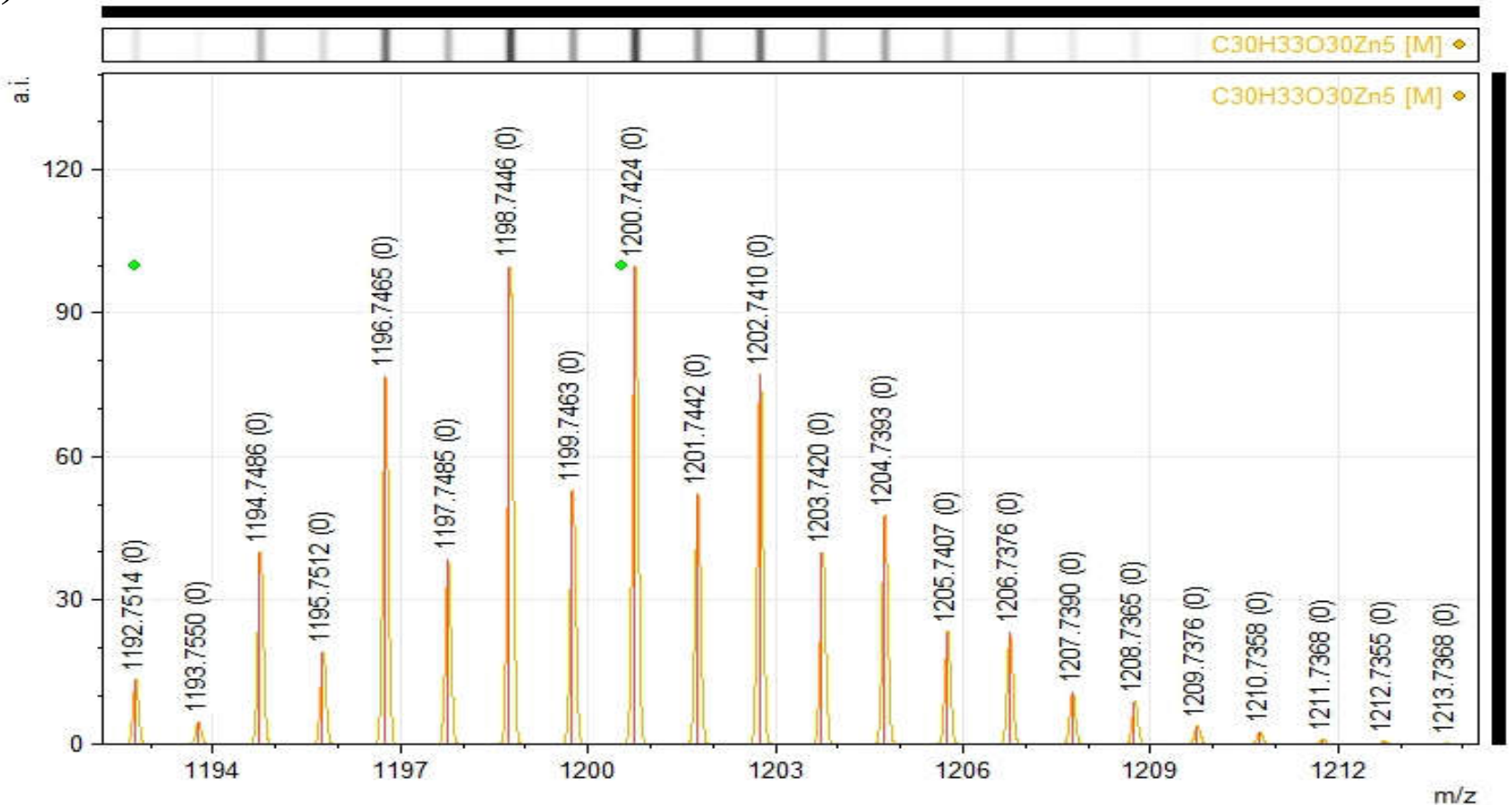

(B)

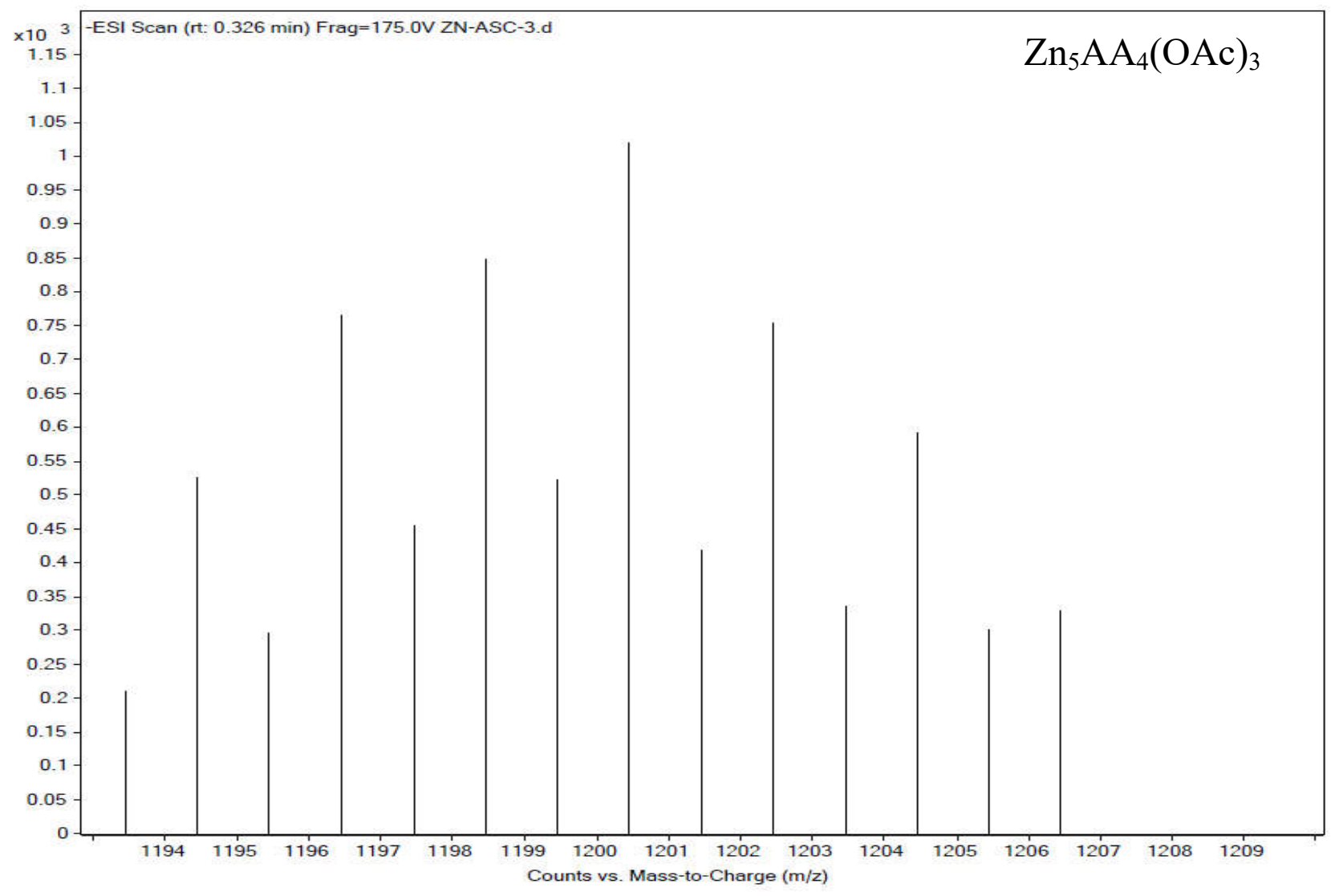


(C)
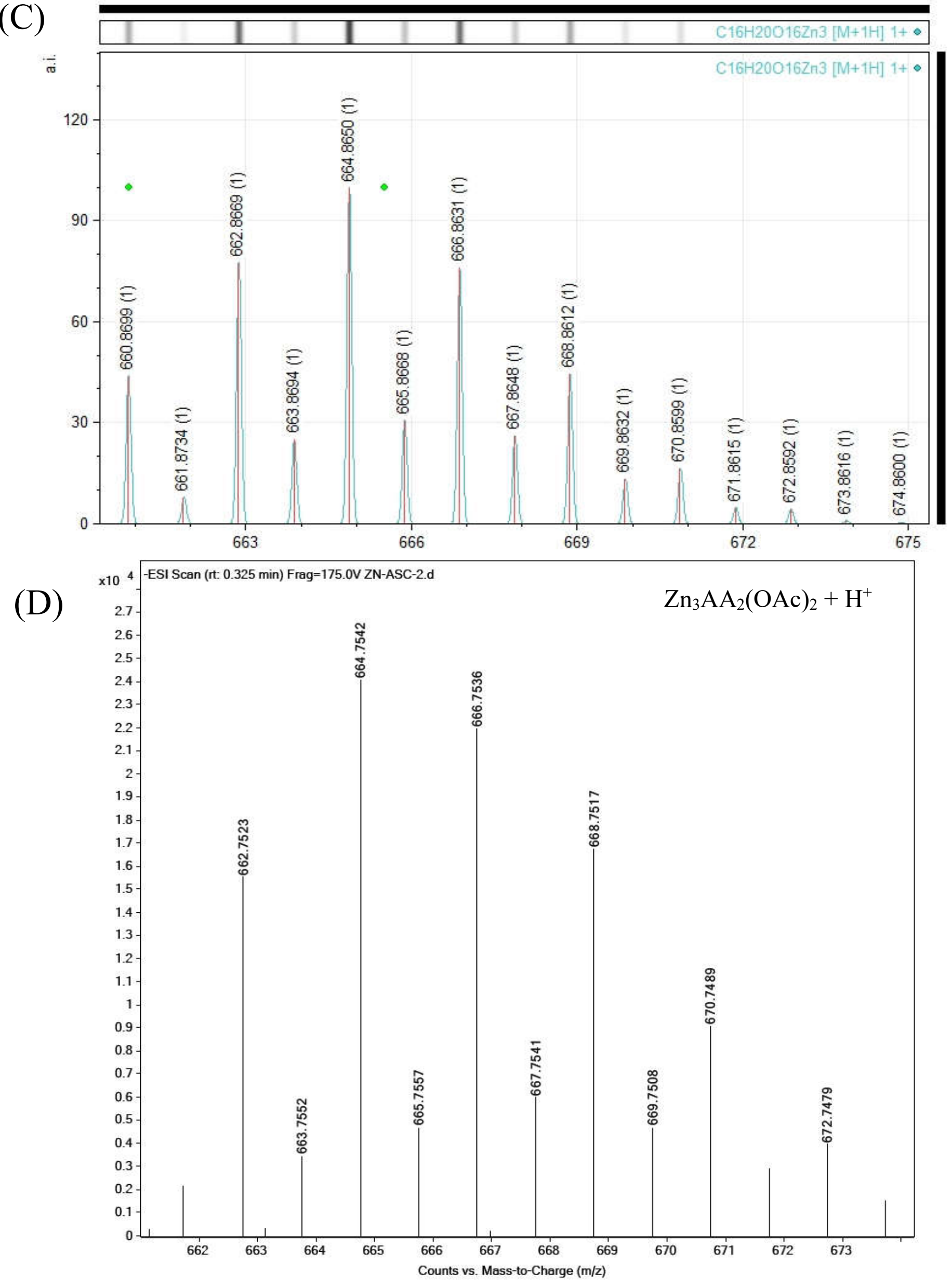
(E)

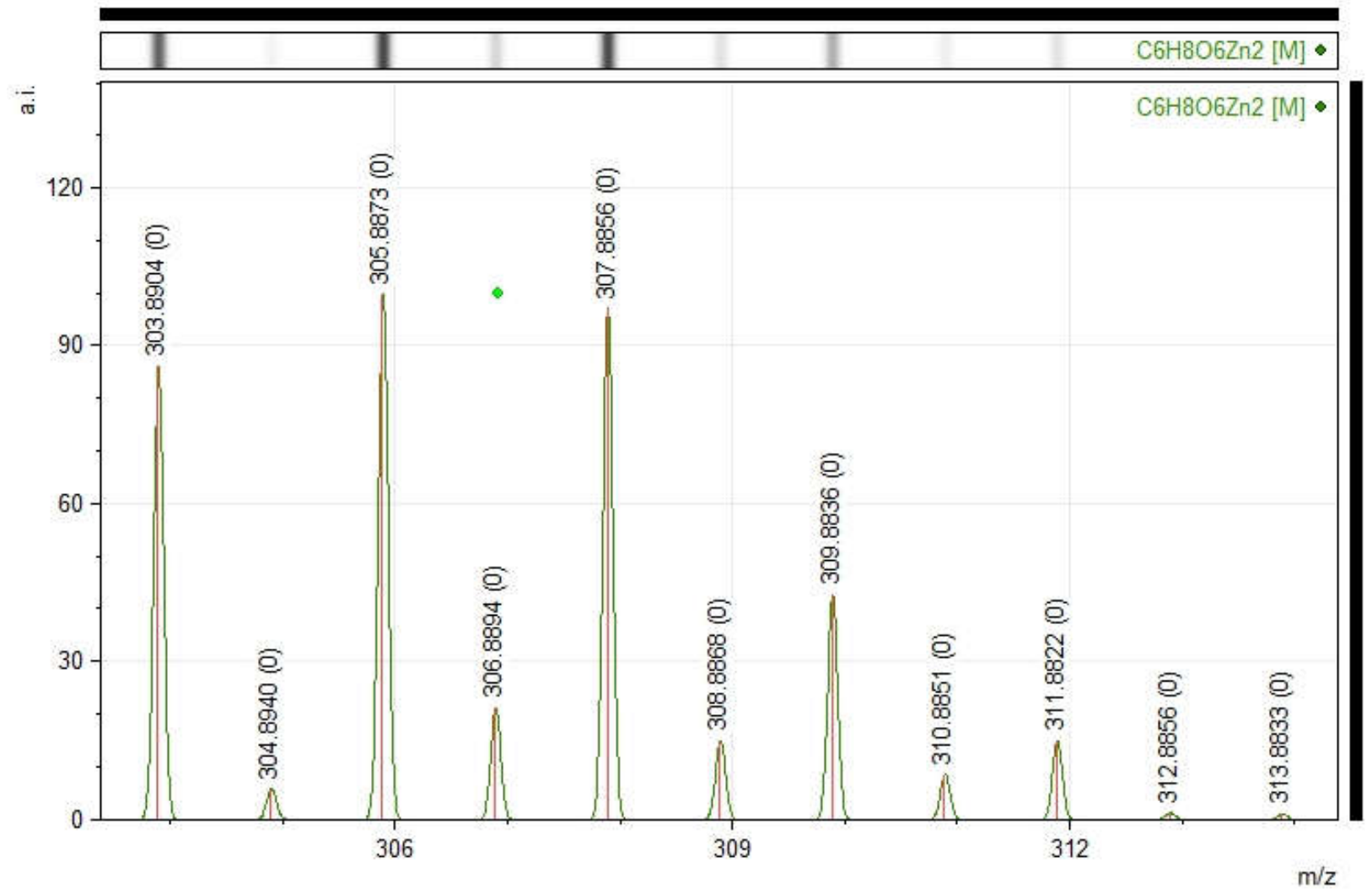

(F)

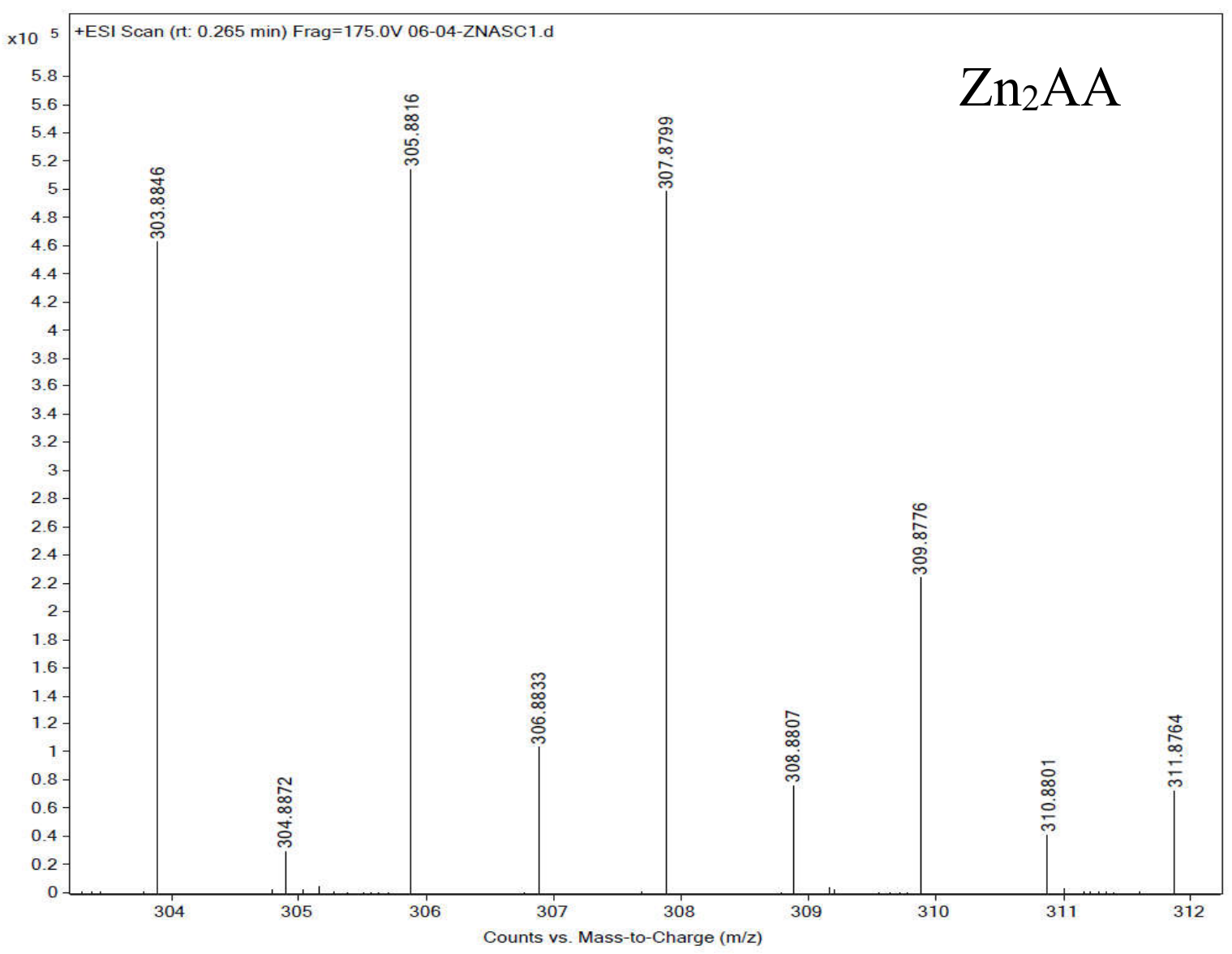


(G)

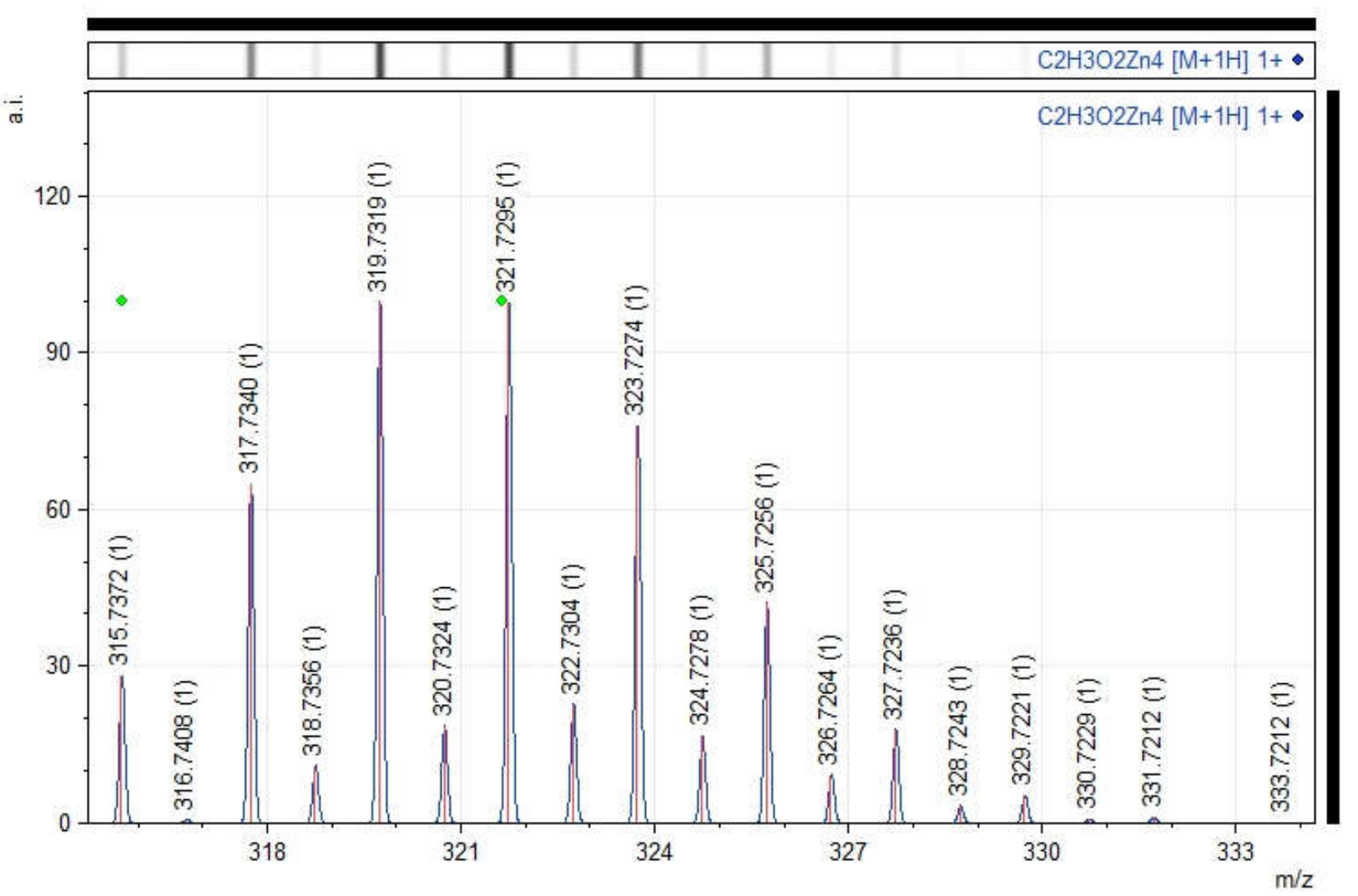

(H)

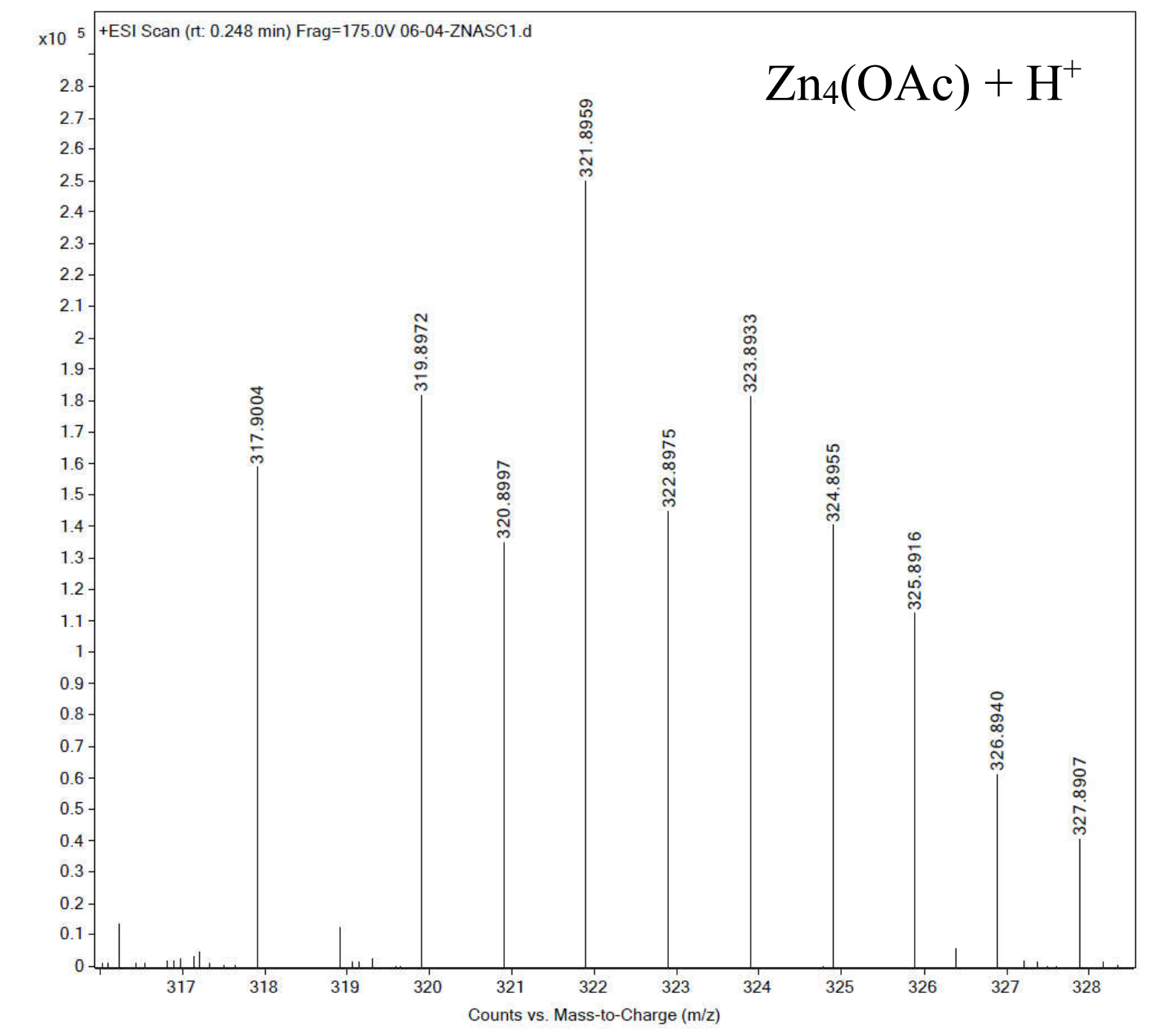


Figure S8. (A) Simulated mass spectrum of the luminescent dispersion indicating presence of $\mathrm{Zn}_{5} \mathrm{AA}_{4}(\mathrm{OAc})_{3}$. (B) Experimental mass spectrum of $\mathrm{Zn}_{5} \mathrm{AA}_{4}(\mathrm{OAc})_{3}$. (C) Simulated mass spectrum of the luminescent dispersion indicating presence of $\mathrm{Zn}_{5} \mathrm{AA}_{4}(\mathrm{OAc})_{3}$. (D) Experimental mass spectrum of $\mathrm{Zn}_{3} \mathrm{AA}_{2}(\mathrm{OAc})_{2}+\mathrm{H}^{+}$. (E) Simulated mass spectrum of the luminescent dispersion indicating presence of $\mathrm{Zn}_{2} \mathrm{AA}$. (F) Experimental mass spectrum of $\mathrm{Zn}_{2}$ AA. (G) Experimental mass spectrum of the luminescent dispersion indicating presence of $\mathrm{Zn}_{4}(\mathrm{OAc})+\mathrm{H}^{+}$. (H) Experimental mass spectrum of $\mathrm{Zn}_{4}(\mathrm{OAc})+\mathrm{H}^{+}$.

(A)

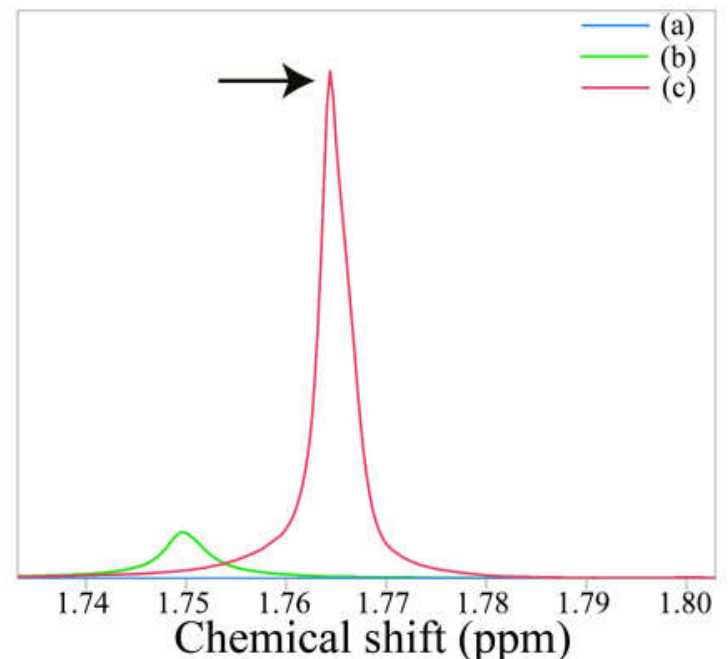

(C)

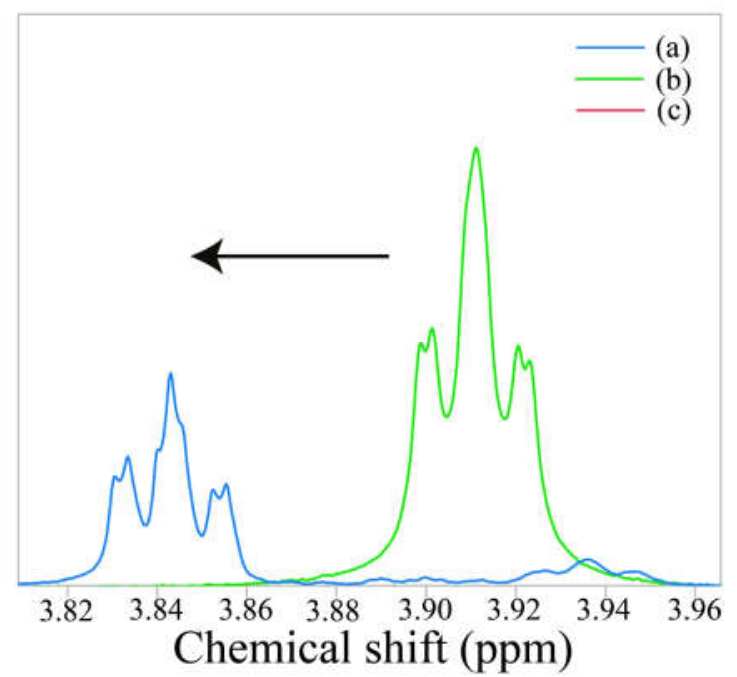

(B)

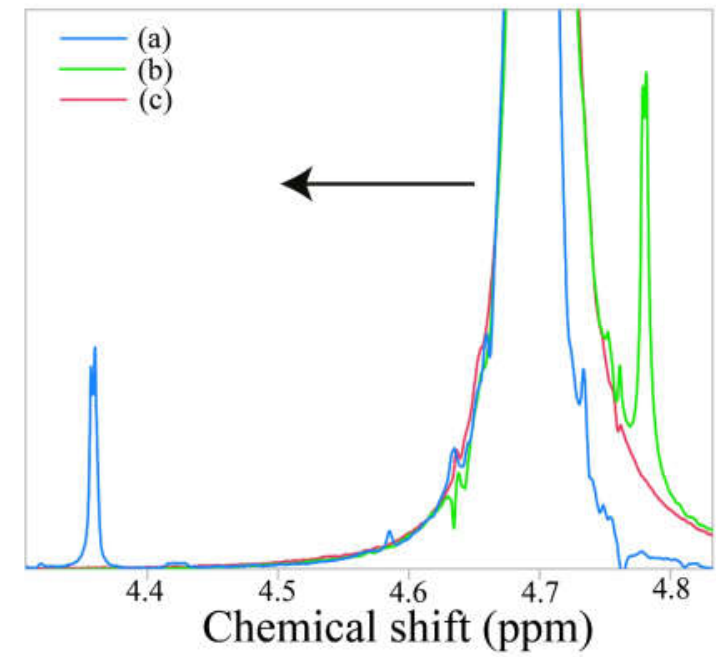

(D)

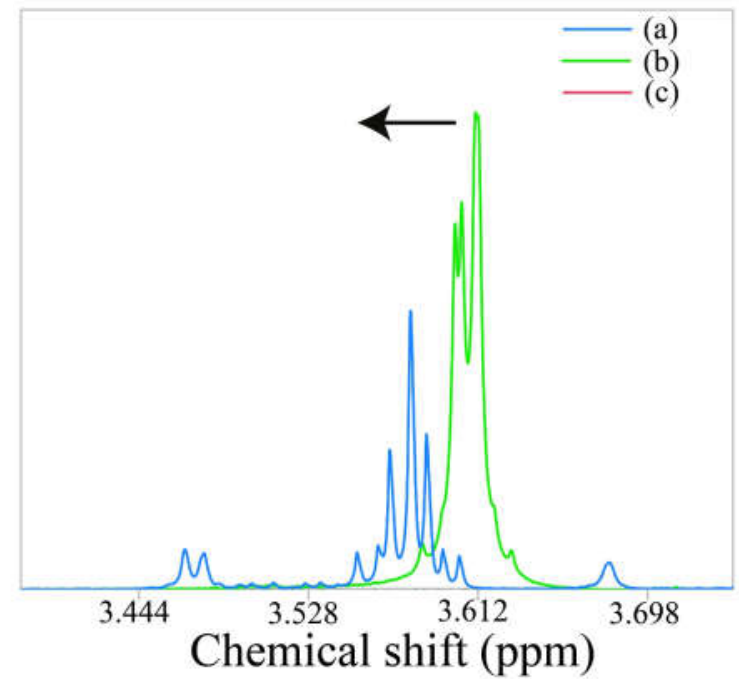

Figure S9 (A-D). Expanded NMR spectra of dispersion of (a) $\mathrm{Zn}_{3}(\mathrm{AA})(\mathrm{OAc})_{2}$, (b) ascorbic acid and (c) zinc acetate, highlighting the chemical shifts of $\mathrm{Zn}_{3}(\mathrm{AA})(\mathrm{OAc})_{2}$ as compared to ascorbic acid and zinc acetate. The spectra refer to the those in Figure 5 in the manuscript. 


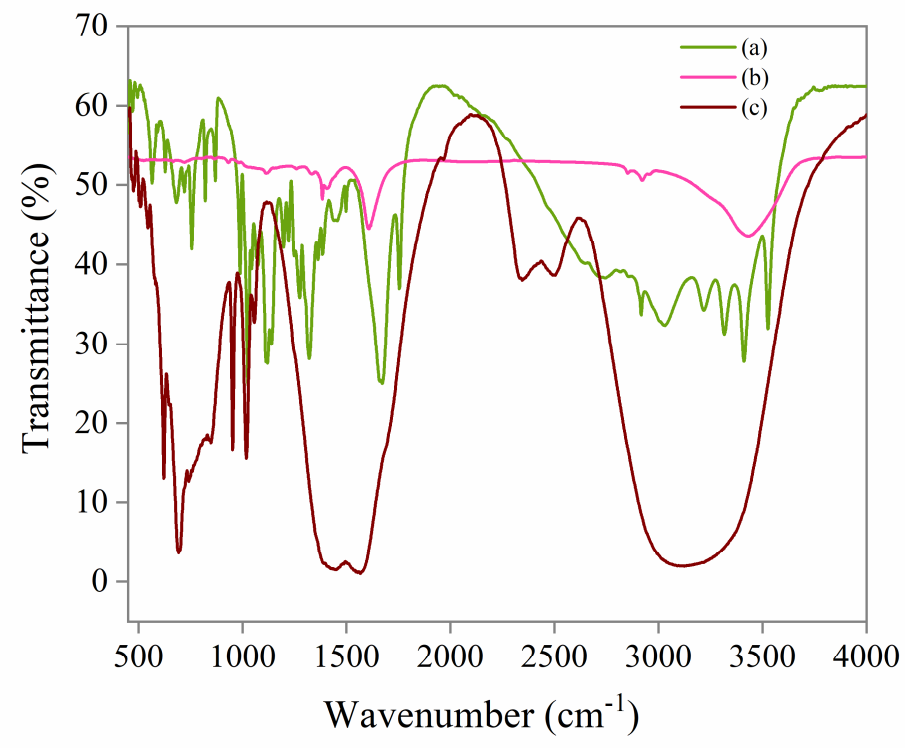

Figure S10. FTIR spectra of (a) ascorbic acid, (b) $\mathrm{Zn}_{3}(\mathrm{AA})(\mathrm{OAc})_{2}$ and (c) zinc acetate.

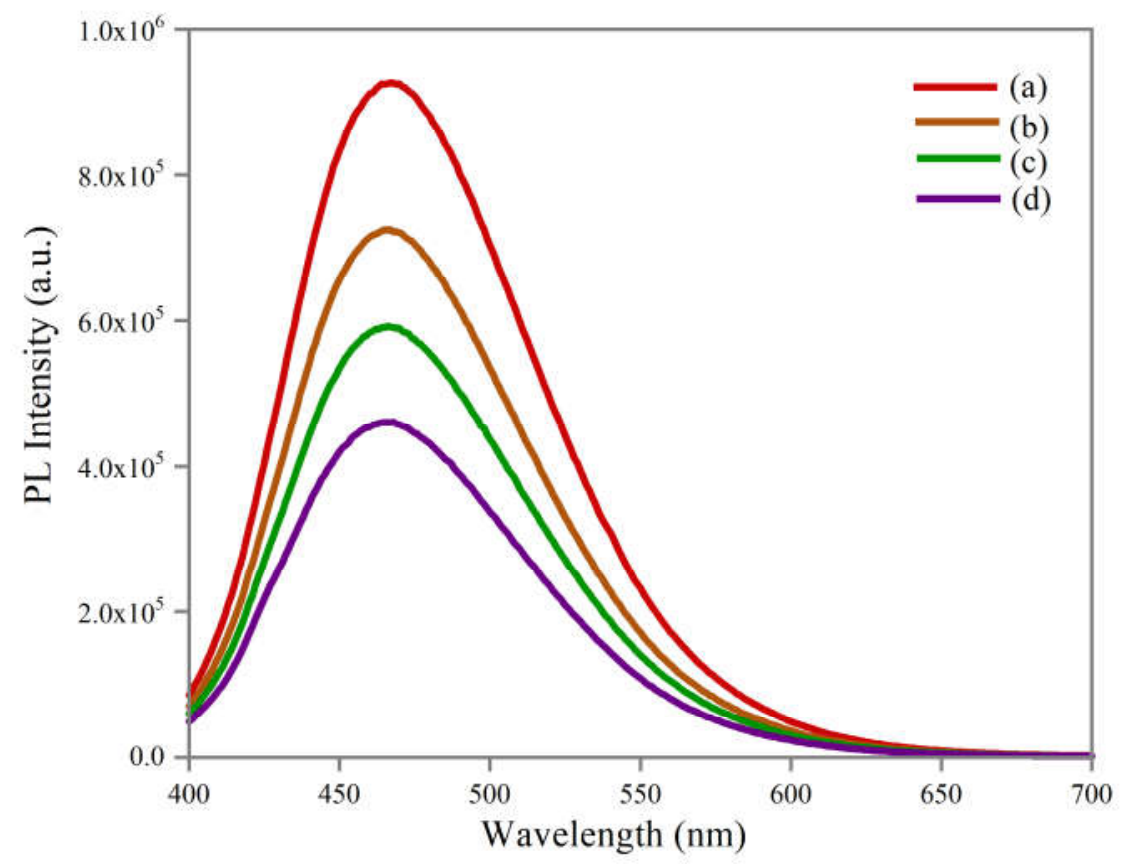

Figure S11. Photoluminescence spectra of (a) $2 \mathrm{~mL}$ of $\mathrm{Zn}_{3}(\mathrm{AA})(\mathrm{OAc})_{2}$ nanoparticle dispersion. $2 \mathrm{~mL}$ of dispersion was added with either (b) $500 \mu \mathrm{L}$ of water. (c) $1000 \mu \mathrm{L}$ water or (d) $1500 \mu \mathrm{L}$ water. The excitation wavelength was set at $371 \mathrm{~nm}$. 
Table S1: Experimentally observed and theoretically simulated mass fragments and their corresponding assignments.

\begin{tabular}{|l|l|l|}
\hline Average mass (observed) & Average mass (simulated) & \multicolumn{1}{c|}{ Component } \\
\hline 305.8816 & 305.8873 & $\mathrm{Zn}_{2} \mathrm{AA}$ \\
\hline \hline 321.7295 & 321.8959 & $\mathrm{Zn}_{4}(\mathrm{OAc})+\mathrm{H}^{+}$ \\
\hline 510.8177 & 510.8147 & $\mathrm{Zn}_{3} \mathrm{AA}(\mathrm{OAc})_{2}+\mathrm{Na}^{+}$ \\
\hline 664.7542 & 664.8650 & $\mathrm{Zn}_{3} \mathrm{AA}_{2}(\mathrm{OAc})_{2}+\mathrm{H}^{+}$ \\
\hline 1200.5 & 1200.7424 & $\mathrm{Zn}_{5} \mathrm{AA}_{4}(\mathrm{OAc})_{3}$ \\
\hline
\end{tabular}

Table S2: Details of chemical shifts of protons of $\mathrm{Zn}_{3}(\mathrm{AA})(\mathrm{OAc})_{2}$ vis-à-vis zinc ascorbate (as per literature reports)

\begin{tabular}{|c|c|c|c|c|}
\hline \multirow{2}{*}{$\begin{array}{l}\text { Types } \\
\text { of } \\
\text { proton }\end{array}$} & \multicolumn{2}{|c|}{ Chemical shift ( $\delta$ ) } & \multicolumn{2}{|c|}{ Splitting Pattern } \\
\hline & $\begin{array}{l}\mathrm{Zn}_{3}(\mathrm{AA})(\mathrm{OAc})_{2} \\
\mathrm{NPs}\end{array}$ & $\begin{array}{ll}\text { Zine } & \text { ascorbate (As } \\
\text { per } & \text { literature } \\
\text { reports) } & \end{array}$ & $\mathrm{Zn}_{3}(\mathrm{AA})(\mathrm{OAc})_{2} \mathrm{NPs}$ & $\begin{array}{lr}\text { Zinc } & \text { ascorbate (As } \\
\text { per } & \text { literature } \\
\text { reports) } & \end{array}$ \\
\hline $\mathrm{H}_{\mathrm{a}}$ & 4.35 & 4.48 & doublet & doublet \\
\hline $\mathrm{H}_{\mathrm{b}}$ & 3.84 & 3.97 & multiplet & multiplet \\
\hline $\mathrm{H}_{\mathrm{c}}, \mathrm{H}_{\mathrm{d}}$ & 3.56 & $3.67-3.70$ & multiplet & multiplet \\
\hline $\mathrm{H}_{\text {acetate }}$ & 1.76 & ----- & singlet & ----- \\
\hline
\end{tabular}

